\title{
"Uno piensa el bayo y otro el que lo filma": La gitanilla de Manuel Aguado (TVE, 1970) ${ }^{1}$
}

\author{
Victoria Aranda Arribas \\ Universidad de Córdoba
}

Título: "Uno piensa el bayo y otro el que lo filma": La gitanilla de Manuel Aguado (TVE, 1970).

Resumen: Del 13 al 17 de abril de 1970, Televisión Española emitió La gitanilla, serie de cinco capítulos basada en la primera de las Novelas ejemplares (1613) de Cervantes. Dirigida por Manuel Aguado, el guion corrió a cargo de Rodrigo Rubio y Rosa Romá. Este artículo analiza sus vínculos con el relato del complutense: por un lado, se sondea aquí el trasvase de los diálogos y poemas al libreto televisivo; por otro, las huellas del binomio "idealismo-realismo", tan característico de la historia de Preciosa y Juan de Cárcamo.

Palabras clave: Cervantes, La gitanilla, Rodrigo Rubio, Rosa Romá, Manuel Aguado, Novela, adaptación televisiva.

Fecha de recepción: 8/6/2021.

Fecha de aceptación: 2/8/2021.
Title: "Uno piensa el bayo y otro el que lo filma": Manuel Aguado's La Gitanilla (TVE, 1970).

Abstract: Between the $13^{\text {th }}$ and the $17^{\text {th }}$ April 1970, Televisión Española showed La Gitanilla, a five episodes series based on the first one of the Exemplary Novels (1613) by Cervantes. Directed by Manuel Aguado, the script was written by Rodrigo Rubio and Rosa Romá. This paper analyzes its links to the Baroque text: on the one hand, I will deal with the transferring of the dialogues and poems from the novel to the script; secondly, I will look into the remains of the "idealism-realism" pairing, so characteristic of Preciosa and Juan de Cárcamo's story.

Key words: Cervantes, La Gitanilla, Rodrigo Rubio, Rosa Romá, Manuel Aguado, Novela, Television Adaptation.

Date of Receipt: 8/6/2021.

Date of Approval: 2/8/2021.

1 Este artículo se inscribe en el marco del Proyecto de Excelencia I+D+i del MINECO La novela corta del siglo XVII: estudio y edición (y III) (FFI2017-85417-P) y del Proyecto I+D+i del Programa Operativo FEDER Andalucía Prácticas editoriales y sociabilidad literaria en torno a Lope de Vega (UCO-1262510). 


\section{Caravana de Preciosas: La gitanilla en escena}

Entre las doce Novelas ejemplares (1613) de Cervantes, La gitanilla es una de las que ha despertado mayor interés. Y no solo por parte de la crítica². La historia de Preciosa pronto se convirtió en una fecunda simiente dentro del imaginario colectivo; de ahí que sus nexos con otros textos suelan girar en torno a la protagonista, cuyos ecos alcanzan hasta nuestros días ${ }^{3}$. No en balde, se trata del relato cervantino que ha disfrutado de más reescrituras, junto con La ilustre fregona. Sánchez Regueira dio noticia de un total de once adaptaciones teatrales ${ }^{4}$ :

a) La Belle Egyptienne (1615) de Alexandre Hardy, comedia';

b) The Spanish Gypsie (1623-1624) de Thomas Middleton y William Rowley, mezcla de La gitanilla con La fuerza de la sangre;

2 Agustín González de Amezúa, Cervantes, creador de la novela corta española, tomo II, Madrid, CSIC, p. 5, la considera "una de sus mejores novelas"; Juan Bautista Avalle-Arce, "Introducción" a Miguel de Cervantes, Novelas ejemplares I, ed. Juan Bautista Avalle-Arce, Madrid, Castalia, 1982, pp. 9-37 (p. 21), se rinde ante la figura de Preciosa, "la más cautivadora y lograda de sus creaciones femeninas"; mientras que Florencio Sevilla Arroyo y Antonio Rey Hazas, "Introducción" a Miguel de Cervantes, La gitanilla. El amante liberal, eds. Florencio Sevilla Arroyo y Antonio Rey Hazas, Madrid, Alianza, 1996, pp. I-LXviII (p. Xxi), opinan que el carácter extraordinario del texto "destaca ya a partir de la mera elección del tema gitanesco, inédito hasta entonces [...]. Y qué decir del personaje femenino central, completamente admirable y sorprendente por muchas razones [...]; y qué de su enamorado, capaz de renunciar a su condición de caballero rico por merecer el amor de una mísera gitana". Finalmente, William H. Clamurro, "Enchantment and Irony: Reading La gitanilla", en A Companion to Cervantess' "Novelas ejemplares", ed. Stephen Boyd, Londres, Tamesis, 2005, pp. 69-84 (p. 69), la define como "the most deceptively complex of all the Novelas ejemplares".

3 Katerina Vaiopoulos, De la novela a la comedia: las "Novelas ejemplares" de Cervantes en el teatro del Siglo de Oro, Vigo, Academia del Hispanismo, 2010, p. 117.

4 Manuela Sánchez Regueira, "La gitanilla en la novela, La gitanilla en el teatro", en Cervantes, su obra y su mundo: actas del I Congreso Internacional sobre Cervantes, dir. Manuel Criado del Val, Madrid, EDI-6, 1981, pp. 437-444 (p. 438).

5 Ver Rafael Ruiz Álvarez, "La transferencia de géneros, modelo de interpretación de otra cultura: A. Hardy", en Traducción y adaptación cultural: España-Francia, coords. Francisco Lafarga y María Luisa Donaire Fernández, Oviedo, Universidad de Oviedo, 1991, pp. 243-252. 
c) entre 1637 y 1643, los holandeses J. Kats, Katarina Werwers y Mattheus G. Tengnagel versificaron la novela;

d) La Belle Egyptienne (1642) de Monsieur de Sallebray, comedia ${ }^{6}$;

e) La gitanilla de Madrid (1671) de Antonio Solís, comedia ${ }^{7}$

f) Die Zigeuner (1777) de Heinrich Ferdinand Möller, comedia;

g) Preciosa (1821) de Pius Alexander Wolff;

h) The Spanish Student (1843) de Henry Wadsworth Longfellow ${ }^{8}$;

i) The Bohemian Girl (1843), ópera de Alfred Bunn y William Balfe';

j) Preziosa (1845), dramma lirico de Ruggero Manna, con texto de Carlo Ettore Colla;

k) Preziosa (1879) de Antonio Smareglia, otro dramma lirico.

A este corpus Vaiopoulos añadiría otros cuatro títulos de origen italiano ${ }^{10}$ : Signorina zingaretta (1646) de Florido De Silvestris; La finta zingara (1651) de Reinaldo Sgambati; Con le borasche in porto, overo la zingaretta di Madrid (1691); y, por fin, Il zingaro per amore (1775) de Francesco

6 Ver Daniele Dalla Valle, "Novella / tragicomedia: dalla novella spagnola alla tragicomedia francese", en Riscrittura, intertestualità, transcodificazione, eds. Emanuella Scarano y Donatella Diamanti, Pisa, Tipografia Editrice Pisana, 1992, pp. 207-215.

7 Se incluye en la Parte treinta y siete de comedias nuevas escritas por los mejores ingenios de España (Madrid, Melchor Alegre / Domingo Palacio y Villegas). Existe una segunda redacción, titulada La gitanilla, cuya autoría se ha atribuido tanto al citado Solís como a Pérez de Montalbán. Según Vaiopoulos, op. cit., pp. 138-139, "los cambios de las dramatis personae crean el típico reparto de la comedia de enredo y, al mismo tiempo, producen los mecanismos de reconstrucción de la acción [...]. Los puntos de contacto entre los textos son limitados y las escisiones eliminan la mayor parte del material diegético de la novela, [lo cual permite] reducir el tiempo a un solo día y el espacio a una ciudad [Toledo]".

8 Ver Eulalia C. Piñeiro Gil, "The Spanish Student y La gitanilla: del convencionalismo a la rebeldía”, REDEN: Revista Española De Estudios Norteamericanos, VIII (1994), pp. 81-92.

9 Ver Julián Jesús Pérez Fernández, "La Gitanilla y The Bohemian Girl: la trayectoria musical de un tema cervantino", DIGILEC: Revista Internacional de Lenguas y Culturas, I (2014), pp. 42-58; y "The Bohemian Girl de William Balfe y Alfred Bunn a través de algunos fragmentos significativos", DIGILEC: Revista Internacional de Lenguas y Culturas, III (2016), pp. 33-48.

10 Katerina Vaiopoulos, Temi cervantini a Napoli. "La Zingaretta" di Carlo Celano, Firenze, Alinea, 2003, pp. 36-37. 
Cerlone. Últimamente, Alviti ha rescatado La zingara spagnuola (1756), commedia dell'arte a partir de la antedicha versión de Solís ${ }^{11}$; y MonrósGaspar ${ }^{12}$ hizo lo propio con The Gypsy Maid (1861) de William Brough y The Merry Zingara (1868) de William Schwenck Gilbert, parodias ambas de la ópera de Balfe ${ }^{13}$.

Todo ello sin contar las copiosas adaptaciones que se han subido a los escenarios desde $2016^{14}$. Pero la lista de revisiones y transformaciones de La gitanilla podría extenderse ad infinitum. Tanto que entre las tareas pendientes del cervantismo y de la literatura comparada se cuenta el análisis sistemático de la "estirpe internacional" de Preciosa, cuya fortuna puede medirse con la del Tenorio o el mismísimo Quijote. Hasta el extremo de que la excepcionalidad "del gitano cervantino [hace de la protagonista] el punto de partida del personaje en la tradición moderna"15.

11 Roberta Alviti, "Canovacci y argomenti de derivación española en el repertorio de la commedia dell'arte en la corte de Augusto III de Sajonia", Hipogrifo: Revista de Literatura y Cultura del Siglo de Oro, viII, 2 (2020), pp. 421-431.

12 Laura Monrós-Gaspar, "La gitanilla en el teatro cómico victoriano. Textos y contextos", Anales cervantinos, XLIX (2017), pp. 271-293.

13 Ver Monrós-Gaspar, op. cit., p. 276. Esta misma autora menciona además los ballets La Gitana (Schmidt y Filippo Taglioni, 1838) y The Gipsy (Benoist, Thomas, Marliani, MM. De Saint-Georges y Mazillier, 1839), el drama The Gitanilla; or the Children of de Zincali (J. Crawford Wilson, 1860) y las comedias Arline; or the Fortunes and Vicissitudes of a Bohemian Girl (William y Robert Brough, 1851), The Bohemian Girl (anónimo, 1861), Arline the Lost Child; or The Pole, the Policeman and the Polar Bear (Henry Bellingham, 1864) y The Bohemian G'yrul (Henry James Byron, 1877).

14 Por citar algunos ejemplos españoles de los últimos ańos, en 2016, con motivo del cuarto centenario de la muerte de Cervantes, la Compañía de Danza Flamenca Carmen Cortés la representó en un espectáculo con coreografía de la propia Cortés y música de Aquilino Jiménez y Jonatan Giménez (https://elpais.com/ tematicos/2016/10/04/elpaismas/1475566227_049419.html; consultado el 05/01/2021); en 2017, Gonzala Martín Scherman hibridó La gitanilla y La ilustre fregona en Constanza, para la compañía Factoría Teatro (https://estudioschinca.com/ Espectaculo/La-gitanilla.html; consultado el 05/01/2021); y Santiago Delgado y Paco Macià la adaptaron en 2018, bajo la dirección de este último (https://www. arenateatro.info/espectaculos/teatro/la-gitanilla/; consultado el 05/01/2021).

15 Jorge García López, "Notas complementarias" a Miguel de Cervantes, Novelas ejemplares, ed. Jorge García López, Madrid, Real Academia Española / Galaxia Gutenberg, 2013, pp. 821-1126 (p. 831). 
Concedo de antemano que mi propósito será menos ambicioso. Si bien la primera de las Ejemplares inspiró un sinnúmero de piezas teatrales, e incluso seis filmes ${ }^{16}$, solo se ha rodado una vez para la pequeña pantalla: La gitanilla (Manuel Aguado, 1970) formó parte de Novela, uno de los programas más aplaudidos en España entre 1964 y $1975^{17}$. Conocido primero como Novela del lunes, sus episodios, de 45 minutos de duración, se emitían el primer día de la semana en horario de sobremesa ${ }^{18}$. Después, su franja se ampliaría a los cinco días laborables, rebautizado ya como Novela. Ofrecía historias seriadas, en tandas de cinco capítulos, que en ocasiones alcanzaron la veintena ${ }^{19}$.

Según García de Castro, "con este nuevo formato [...] se pretendió trasladar [a la] televisión las normas del serial radiofónico para montar un capítulo diario y poder [difundir] una novela a la semana" ${ }^{20}$. Palacio ha explicado a este respecto que

cuando se piensa sobre la televisión, no suele recordarse la producción ingente de ficción que supuso la emisión del espacio Novela durante casi veinte años. [...] Hubo temporadas en que llegaron a programarse dos novelas diarias (a las 15:30 y a las 21:00 horas, con una duración entre los veinte y los treinta minutos por episodio); [...] ya en los setenta, no fue extraordinaria la existencia de novelas que duraban dos, tres y hasta cuatro semanas. Generalizando, puede decirse que en este período de "edad de oro" de los dramáticos, TVE

16 La gitanilla (Adriá Gual, 1914), Arlequines de seda y oro / La gitana blanca (Ricardo de Baños, 1919 / 1923), The Bohemian Girl (Harley Knoles, 1922), La gitanilla (André Hugon, 1923), The Bohemian Girl (James W. Horne, Charley Rogers, 1936) y La gitanilla (Fernando Delgado, 1940). Ver Victoria Aranda Arribas, “"Mi ingenio las engendró y van creciendo en los brazos de la cámara': la novela corta del Barroco en el cine y la televisión”, Janus, Ix (2020), pp. 596-642 (pp. 605-613).

17 Se mantuvo en antena durante casi dos décadas: desde 1962 a 1978. Ver Francisca López, Historias de la pequeña pantalla: representaciones históricas en la televisión de la España democrática, Madrid / Frankfurt, Iberoamericana / Vervuert, 2009.

18 Mario García de Castro, La ficción televisiva popular: una evolución de las series de televisión en España, Barcelona, Gedisa, 2002, p. 31.

19 Para esta serie se realizaron otro par reescrituras de las Ejemplares: Los hombres de cristal (Fernando Delgado, 1966) —basada en El licenciado Vidriera- y La ilustre fregona (Gabriel Ibáñez, 1978).

20 Ibidem, p. 32. 
producía unas 30-50 novelas anuales que incluían adaptaciones de obras de autores extranjeros, [pero también españoles,] y guiones originales $^{21}$.

La gitanilla se televisó del 13 al 17 abril de 1970. Habitual en las producciones del ente público, Manuel Aguado, su realizador, participaría en varias de las series literarias de entonces: Teatro de siempre (El enfermo imaginario, 1979); Teatro breve (Gazpacho andaluz, 1980); Ficciones (El rumor, 1980) y Estudio 1 (Cuando llegue el dia, 1970; La viudita naviera, 1976; La Venus de Milo, 1980; y La mamma, 1983, entre otras) ${ }^{22}$. Para Novela dirigiría más de cincuenta entregas (Emma de Jane Austen, 1967; La pródiga de Pedro Antonio de Alarcón, 1975; Pepita Jiménez de Juan Valera, 1978... $)^{23}$, destacando su Ensayo general para un Siglo de Oro (1971), original metaficción —escrita por el dramaturgo Carlos Muñiz- que recreaba la Espańa del Seiscientos a través de distintas figuras históricas: Teresa de Jesús, san Juan de la Cruz, Quevedo, Cervantes... ${ }^{24}$

El guion de La gitanilla corrió a cargo del matrimonio formado por Rosa Romá y Rodrigo Rubio. Por lo que atañe a la primera, solo tenemos constancia de un par de colaboraciones en Novela, siempre junto a su marido (Elia, Manuel Ripoll, 1972; Sinfonia familiar, Manuel Ripoll,

21 Manuel Palacio, Historia de la televisión en España, Barcelona, Gedisa, 2001, p. 147.

22 Estudio 1 (1965-1984) fue el más longevo y exitoso de los programas de "dramáticos", o sea, de teatro grabado; un género al que también pertenece $L a$ gitanilla de Novela. A su zaga, surgieron otros formatos hermanos, con pequeñas diferencias entre sí: Teatro de siempre (1966-1979) se caracterizaba por la exclusiva emisión de piezas clásicas, pero luego incorporaría títulos de la edad moderna y contemporánea. Teatro breve (1966-1981) no solía exceder los treinta minutos de metraje. Finalmente, en Ficciones (1971-1981) se dio el "predominio de lo fantástico y de guiones originales [...] de autores poco conocidos" (Luis Miguel Fernández Fernández, "Varia (I): Dramáticos 1973-1979", en Televisión y Literatura en la España de la Transición (1973-1982), eds. Antonio Ansón et al., Zaragoza, Institución Fernando el Católico, 2010, pp. 373-380 (pp. 373-374)).

23 IMDb (https://www.imdb.com/name/nm1651723/, consultado el 09/01/2021) registra un total de 57, pero no incluye entre ellas La gitanilla de 1970, por lo que cabe suponer más de una laguna dentro del corpus.

24 Ver en la web de Televisión Española: https://www.rtve.es/alacarta/videos/ensayogeneral-para-un-siglo-de-oro/ensayo-general-para-siglo-oro-capitulo-1/3715278/ (consultado el 09/01/2021). 
$1974)^{25}$, mientras que Rubio es más conocido como narrador (Un mundo a cuestas, 1961, Premio Gabriel Miró; Equipaje de amor para la tierra, 1965, Premio Planeta; Papeles amarillentos en el arca, 1970, Premio Álvarez Quintero). Miembro de la Generación del Medio Siglo y cultivador del realismo crítico, sus novelas se definen por "la lucha continua del hombre por sobrevivir, las miserias que lo rodean y acosan, la soledad que le oprime" ${ }^{26}$. Su trabajo en televisión se redujo a cuatro espacios: Las malas lenguas (Arturo Ruiz y Guillermo Ziener, 1968), La herida (en Pequeño estudio, Manuel Aguado, 1969), La onza de oro (Jaume Picas, 1975) y Una mano inocente (José Carlos Garrido, 1977) (ambas en Original). Para Novela, al margen de los dos libretos escritos con su mujer, se encargó de Pequeñeces (también de Manuel Aguado, 1976) y Equipaje de amor para la tierra (Francisco Abad, 1977), adaptación de su obra homónima ${ }^{27}$.

Encabezaron el reparto de La gitanilla Tina Sainz (Preciosa), Luis Varela (Juan Cárcamo) ${ }^{28}$ y Nicolás Dueñas (Clemente, el paje-poeta). Y según acostumbra a suceder en este tipo de producciones, la crítica le dio una de cal y otra de arena. Por ejemplo, el diario $A B C$ publicaba la siguiente reseña:

La gitanilla es, quizá, la más popular de las Novelas ejemplares de Cervantes. Era difícil expresarla en televisión por la compleja escenografía, la sugestión del ambiente y la autenticidad de los tipos y su circunstancia de raza. Todo fue salvado con holgura merced a la estupenda adaptación televisual hecha por Rodrigo Rubio y Rosa Romá, que supieron mantener en el guion toda la gracia y frescura, encanto y garra de La gitanilla. Feliz interpretación de Tina Sainz. Manuel Aguado se recreó recreando [sic] La gitanilla, pese a los innumerables obstáculos acumulados que Francisco Sanabria, decorador de TVE, salvó con indudable agilidad ${ }^{29}$.

25 https://www.imdb.com/name/nm4660977/?ref_=tt_ov_wr (consultado el 05/01/2021).

26 Manuel Cifo González, La novelistica de Rodrigo Rubio: aproximación al realismo crítico, Murcia, Universidad de Murcia, 1977 [tesina de licenciatura], p. 214.

27 https://www.imdb.com/name/nm0748377/?ref_=tt_ov_wr (consultado el 05/01/2021).

28 Varela también encarnó a Diego de Carriazo en la versión de La ilustre fregona dirigida por Gabriel Ibáńez para Novela (1978).

29 "Cervantes", $A B C(19 / 04 / 1970)$, p. 70. 
Bien distinto fue el parecer de Baget Herms, quien, tras el estreno de $E l$ casamiento engañoso (Hora 11, Luis Calvo Teixeira, 1970) —escrita por Juan Tébar y estrenada apenas un mes después de La gitanilla-, le negó el pan y la sal a la adaptación de Aguado:

[Luego] de comprobar el muy mediocre resultado de La gitanilla en Novela, estamos dispuestos a aceptar toda clase de innovaciones y entre ellas la de Tébar, que nos pareció inteligente y humorística, con apuntes críticos muy dignos de ser destacados sobre nuestra sociedad y su sentido de las apariencias. Entre la libérrima adaptación de El casamiento... y la apolillada mise en scène de La gitanilla, donde naufragó el espíritu de las novelas cervantinas, nos quedamos con la primera ${ }^{30}$.

Como se verá, coincido en lo sustancial con el crítico catalán, toda vez que, a pesar de los esfuerzos del equipo de Novela para ambientar el relato en estudio, la miniserie pecó a menudo de costumbrista, dejando atrás la ambigüedad e ironía cervantinas. Sin embargo, no carece de interés; y, según advertiremos, en el epílogo se percibe siquiera un eco de la esencia del relato. En paralelo, esta Gitanilla se erige como una valiosa muestra de la ficción televisiva de los setenta, que extraería más de un filón del mundo de las letras ${ }^{31}$. TVE siguió así la estela de otros países que habían potenciado ya el traslado de su narrativa al nuevo medio; y tampoco dudaría en sumarse al heritage cinema, que se esmeraba en reconstruir épocas pasadas, como es el caso de La gitanilla de Aguado.

Primero sondearé las estrategias que Rubio y Romá — siempre en aras de la agilidad - desplegaron para convertir la novela en un guion; en segundo lugar, incidiré sobre aquellos cambios, en apariencia triviales, que despojaron a La gitanilla de sus prendas más misteriosas, distintivas y meritorias.

30 Josep María Baget Herms, “El casamiento engañoso”, Imagen y Sonido, Lxxxv (1970), pp. 57-58 (p. 58).

$31 \mathrm{Al}$ igual que ocurriera en los albores del cine, durante los primeros ańos de la pequeńa pantalla, la literatura resultó crucial para su desarrollo. Se trataba de un matrimonio que le permitía matar dos pájaros de un tiro: entretener y enseñar a un público cada vez más diverso. Ver Manuel Palacio, "Enseñar deleitando. Las adaptaciones literarias en televisión”, Cuadernos de la Academia, XI-XII (2002), pp. 519-537. 


\section{Desordenar PARA ENTRETENER: LA TRANSPOSICIÓN ${ }^{32}$}

La primera de las Novelas ejemplares gira alrededor de Preciosa, una gitanilla que atrae las miradas de propios y extraños con su discreción y gracia al bailar. En Madrid, don Juan de Cárcamo, un noble galán, se prenda de ella y le propone matrimonio. Preciosa aceptará con la condición de que su pretendiente conviva junto a los suyos durante un par de ańos. Si entonces Juan mantiene vivos sus sentimientos, estará dispuesta a casarse con él. Rebautizado como Andrés, el caballero se adapta a su nueva vida, aunque se abstendrá de delinquir.

Los conflictos que surgen entre ambos tienen dos nombres propios: Clemente y Juana Carducha. El primero es un paje-poeta que en Madrid regalaba con sonetos a Preciosa; su visita al aduar despertará los celos de Andrés, hasta que se descubre que Clemente había huido de la justicia y no lo mueve ninguna aspiración amorosa. Durante su viaje hacia Murcia, los gitanos se alojan en una posada en la que entrará en escena Juana Carducha, la hija de la propietaria. Enamorada de Andrés y despechada por su causa, meterá algunas de sus joyas entre los bártulos del mancebo y lo denunciará a las autoridades. Al descubrirlas, un soldado abofetea al presunto ladrón, que, recobrando su aristocrático orgullo, no tardará en darle muerte. Andrés acaba preso y será condenado a la horca.

La protagonista, con la voluntad rendida a don Juan / Andrés, queda devastada por la noticia. Incapaz de verla sufrir, su abuela la llevará ante los corregidores de Murcia. Una vez allí, confiesa que Preciosa es en realidad Constanza, la hija perdida de los nobles, a la cual secuestró cuando era niña. Entonces, los padres lloran de alegría y abrazan a la joven, que les suplica la liberación de su caballero, con el que finalmente contraerá matrimonio.

Por su parte, La gitanilla televisiva se estructuró en cinco capítulos:

I. (13/04/1970). Un grupo de gitanas baila en una plaza. Un teniente se fija en Preciosa (Tina Sainz), y manda a su paje (Nicolás

32 Sergio Wolf, Cine/Literatura. Ritos del pasaje, Barcelona, Paidós, 2001, p. 16, prefiere hablar de "transposición", que alude a una operación de "traslado" y "trasplante", alejándose de la voz "adaptación", que para él implica un intento de forzar que la literatura "quepa en el cine", con la consiguiente devaluación de este último. 
Dueñas) para que la reciba en su casa junto a su abuela (Mercedes Prendes). El citado paje entrega un soneto a Preciosa. Lo leerán durante la visita al militar y su mujer, antes de que la cíngara le diga la buenaventura a esta última, haciendo gala de su agudeza y discreción. Juan Cárcamo (Luis Varela), uno de los invitados, ve a la linda gitana y se enamora de ella. Cuando Preciosa abandona la casa, desea hablarle, pero la protagonista retrasa la conversación hasta el día siguiente.

II. (14/04/1970). Por la mañana, Preciosa cumple su palabra. Juan le declara sus sentimientos y ella le pone una serie de requisitos que aceptará sin rechistar. Acuden de nuevo a casa del teniente. Antes de entrar, el poeta le da otro soneto. Vuelven a bailar y Preciosa vaticina el futuro de Juan.

III. (15/04/1970). Los gitanos danzan en un campamento. Juan, ya uno más de su círculo, discute con un viejo (Jorge Orjas) sobre la ejecución o no de una mula. Se celebra el compromiso entre Cárcamo y Preciosa. El anciano proclama las bellezas de la vida calé. Juan pide no robar hasta que se adapte al nuevo contexto. Andando el tiempo, se topará con un joven malherido por unos perros: resulta ser Clemente, el paje-poeta de Madrid. Siente celos de él, pero Preciosa disipa sus dudas y revalida su compromiso.

IV. (16/04/1970). Clemente le desvela a Juan la razón de su visita: huye de un noble que lo perseguía por haber rechazado el casamiento con su hija. Cárcamo propone enseguida que los gitanos lo acompañen hasta Sevilla, donde Clemente se verá con un amigo que lo ayudará a embarcar hacia Italia. La vieja gitana advierte que no quiere ir a la capital hispalense por una picardía que le hizo al gorrero Triguillos. Pero sus compinches la desoyen y emprenden el camino. Se alojarán en una venta. Allí Juan ve a Preciosa charlar con el paje-poeta y vuelve a arder de celos. La mesonera (Julita Trujillo) aborda a Cárcamo y se declara. El noble la rechaza. Preciosa repara en este juego con cierta preocupación. La moza mete un joyero en las alforjas del pollino de Juan.

v. (17/04/1970). Los alguaciles descubren el supuesto robo y se llevan preso a Juan. El resto de gitanos huye, salvo Preciosa y la abue- 
la, que permanecerán en la fonda. Preciosa llora desconsolada. La abuela decide visitar a los corregidores de Sevilla, que no son sino los padres biológicos de la protagonista. Se descubre así el secuestro y su identidad. Preciosa les ruega que excarcelen a Juan, tal como ocurre luego de una visita del corregidor al calabozo para poner a prueba sus sentimientos. La pareja se abraza al fin. Preciosa piensa en la vida que deja atrás.

\subsection{Cortar por lo sano: los diálogos}

Dentro de las Novelas ejemplares, La gitanilla es una de las que posee mayor acción y diálogo, lo cual facilita su metamorfosis teatral o en guion, a diferencia de otras más enigmáticas y menos narrativas, como El licenciado Vidriera. Con todo, Rubio y Romá se vieron obligados a abreviar los poemas y parte del discurso, pues, de lo contrario, los largos monólogos de Preciosa, Juan, la abuela o el viejo gitano habrían interrumpido el ritmo de la serie.

En palabras de Swain, cuando se adapta una obra literaria, "the only solution, obviously, is to cut, cut, cut. The question is: cut what?" ${ }^{3}$. Los guionistas de La gitanilla de Manuel Aguado lo tuvieron claro desde el principio, pues, aparte de recortar los soliloquios y de la elipsis del narrador, no se distanciaron en demasía del original. Sin embargo, al comparar los diálogos novelescos con los televisivos, nos daremos cuenta de que el matrimonio Rubio-Romá no se limitó a usar las tijeras. Cuando una intervención se dilata en exceso, la interrumpen y dinamizan gracias a la réplica del interlocutor de turno; y viceversa, transformando tales monólogos en una suerte de 'taracea dialéctica'.

Veamos un ejemplo. En el relato de Cervantes, los requiebros de Juan a Preciosa se desarrollan en una sola escena compuesta por cinco discursos; por el contrario, en la serie de TVE se divide en dos escenas diferentes - la última del primer capítulo y la primera del segundo, para potenciar el cliffhanger — con parlamentos mucho más breves y numerosos. El lector sabrá disculpar tan prolijo pero necesario paréntesis ${ }^{34}$ :

33 Dwight Swain, Film Scriptwriting, Londres / Boston, Focal Press, 1988, p. 196.

34 Cervantes, op. cit., pp. 55-62. 
- Por vida vuestra, amiga, que me hagáis placer que vos y Preciosa me oyáis aquí aparte dos palabras, que serán de vuestro provecho.

- Como no nos desviemos mucho, ni nos tardemos mucho, sea en buen hora - respondió la vieja. [...]

-Yo vengo de manera rendido a la discreción y belleza de Preciosa, [...]. Yo, señoras mías (que siempre os he de dar este nombre, si el Cielo mi pretensión favorece), soy caballero, [...], soy hijo único, y el que espera un razonable mayorazgo. Mi padre está aquí en la corte pretendiendo un cargo, y ya está consultado, y tiene casi ciertas esperanzas de salir con él. Y, con ser de la calidad y nobleza que os he referido, y de la que casi se os debe ya de ir trasluciendo, con todo eso, quisiera ser un gran señor para levantar a mi grandeza la humildad de Preciosa, haciéndola mi igual y mi señora. Yo no la pretendo para burlalla, ni en las veras del amor que la tengo puede caber género de burla alguna; sólo quiero servirla del modo que ella más gustare: su voluntad es la mía. Para con ella es de cera mi alma, donde podrá imprimir lo que quisiere; y para conservarlo y guardarlo no será como impreso en cera, sino como esculpido en mármoles, cuya dureza se opone
Juan. Por vida vuestra, amiga.

Preciosa. Yo no soy vuestra amiga.

Juan. Por vida vuestra que me hagáis el placer que vos me oigáis aparte unas palabras que serán de vuestro provecho.

Abuela. Como no os alejéis mucho, ni tardéis mucho... Id en buen hora.

Preciosa. Si queréis hablarme, aquí lo habéis de hacer, que lo que yo pueda oír también pueden oírlo ellas.

JuAn. Rendido estoy a vuestra discreción y belleza, Preciosa. Yo, señora, he quedado maravillado ante vuestro donaire de hace un momento. Yo, señora... (Preciosa $y$ las gitanas se rien). Señora, yo...

Preciosa. "Señora"... Es tarde. Si tan importantes son las cosas que queréis decirme, venid aquí mismo mañana y con la luz del día hablaremos. La noche es propicia para engańos.

Juan. Si ese es vuestro deseo... Así lo haré.

Preciosa. (Mirando a cámara como en un ensueño) Así lo haré... Si vos lo deseáis... (Se aleja y deja caer un lazo para que Juan lo recoja).

Juan. Por un momento, temí que no vinieseis.

Preciosa. Pues ya veis que he 
a la duración de los tiempos. $\mathrm{Si}$ creéis esta verdad, no admitirá ningún desmayo mi esperanza; pero si no me creéis, siempre me tendrá temeroso vuestra duda. Mi nombre es éste - $-y$ díjosele-; el de mi padre ya os le he dicho. La casa donde vive es en tal calle, y tiene tales y tales señas; vecinos tiene de quien podréis informaros, y aun de los que no son vecinos también, que no es tan escura la calidad y el nombre de mi padre y el mío que no le sepan en los patios de palacio, y aun en toda la corte. Cien escudos traigo aquí en oro para daros en arra y señal de lo que pienso daros, porque no ha de negar la hacienda el que da el alma. [...]

-Perdóneme, abuela, de que me tomo licencia para responder a este tan enamorado señor.

- Responde lo que quisieres, nieta — respondió la vieja—, que yo sé que tienes discreción para todo.

Y Preciosa dijo:

-Yo, señor caballero, aunque soy gitana pobre y humildemente nacida, tengo un cierto espiritillo fantástico acá dentro, que a grandes cosas me lleva. A mí ni me mueven promesas, ni me desmoronan dádivas, ni me inclinan sumisiones, ni me espantan finezas enamoradas; $y$, aunque de quince años [...], soy ya vieja en los pensamientos [...]. Una sola venido. (Se hace el silencio) ¿Queréis hablar ya de una vez?

Juan. Yo, señora Preciosa, soy caballero, hijo único que espera un razonable mayorazgo. $\mathrm{Y}$ es $\mathrm{mi}$ de seo levantar a la grandeza la humildad de Preciosa haciéndola mi igual y mi señora. Yo no la pretendo para burlarla, ni en las veras del amor que la tengo puede caber género de burla alguna. Solo quiero servirla del modo que ella más gustare. Su voluntad es la mía. Con vos, es de cera mi alma, donde podéis imprimir lo que quisiereis. Y para conservarlo y guardarlo, no será como impreso en cera, sino como esculpido en mármoles cuya belleza se opone a la duración de los tiempos.

Abuela. (Se sienta. Aparte) Sin duda es un caballero, pues solamente un caballero admirara bajo estas prendas la distinción de una señora.

JuAn. Si creéis esta verdad, no admitiré ningún desmayo en mi esperanza; pero si no me creéis, me tendrá temeroso vuestra duda.

Preciosa. ¿Cómo sabré yo que sois sincero?

Juan. Cien escudos traigo yo aquí en oro para daros en alzas y señal de lo que pienso daros, que no ha de negar la hacienda el que da el alma.

Preciosa. Perdóneme, abuela, que me tome licencia para responder a tan enamorado señor 
joya tengo, que la estimo en más que a la vida, que es la de mi entereza y virginidad, y no la tengo de vender a precio de promesas ni dádivas, porque, en fin, será de muy poca estima; [...]. Si quisiéredes ser mi esposo, yo lo seré vuestra, pero han de preceder muchas condiciones y averiguaciones primero. Primero tengo de saber si sois el que decís; luego, hallando esta verdad, habéis de dejar la casa de vuestros padres y la habéis de trocar con nuestros ranchos; y, tomando el traje de gitano, habéis de cursar dos años en nuestras escuelas, en el cual tiempo me satisfaré yo de vuestra condición, y vos de la mía; al cabo del cual, si vos os contentáredes de mí, y yo de vos, me entregaré por vuestra esposa; pero hasta entonces tengo de ser vuestra hermana en el trato, y vuestra humilde en serviros. [...]. Si con estas condiciones queréis entrar a ser soldado de nuestra milicia, en vuestra mano está, pues, faltando alguna dellas, no habéis de tocar un dedo de la mía. [...] No es este caso de tan poco momento, que en los que aquí nos ofrece el tiempo pueda ni deba resolverse. Volveos, señor, a la villa, y considerad despacio lo que viéredes que más os convenga, y en este mismo lugar me podéis hablar todas las fiestas que quisiéredes, al ir o venir de Madrid.
Abuela. Responde lo que quisieres nieta, que yo sé que tienes discreción para todo.

Preciosa. Yo, señor caballero, aunque soy gitana pobre y humildemente nacida tengo un cierto espiritillo fantástico acá dentro que a grandes cosas me lleva. A mí ni me mueven promesas ni me desmoronan dádivas ni me inclinan sumisiones, ni me espantan finezas enamoradas; $y$, aunque de veinte ańos, vieja soy en pensamiento. Una sola joya tengo que la estimo más que a la vida. Y no la venderé a precio de promesas y de dádivas, porque, en fin, será vendida, y si puede ser comprada, será de muy poca estima.

JuAn. Lo único que os pido, si es que puedo ya pediros o suplicaros algo... Que no vengáis más a Madrid.

Preciosa. Eso no, señor galán, ¡sepa que conmigo ha de andar la libertad desenfadada sin que la ahogue o la turbe la pesadumbre de los celos! Y mirad que los amantes que entran pidiendo celos o son simples o desconfiados.

Abuela. ¡Satanás tienes en tu pecho muchacha, que dices cosas que no las dirá un colegial de Salamanca! ¿Tú sabes de amor, tú sabes de celos y desconfianzas? ¿Cómo es eso, que me tienes loca y te oigo como a una persona espiritada que habla latín sin saberlo? 
- Cuando el Cielo me dispuso para quererte, Preciosa mía, determiné de hacer por ti cuanto tu voluntad acertase a pedirme, aunque nunca cupo en mi pensamiento que me habías de pedir lo que me pides; pero, pues es tu gusto que el mío al tuyo se ajuste y acomode, cuéntame por gitano desde luego, y haz de mí todas las esperiencias que más quisieres. [...] Lo que te pido es (si es que ya puedo tener atrevimiento de pedirte y suplicarte algo) que, si no es hoy, donde te puedes informar de mi calidad y de la de mis padres, que no vayas más a Madrid; porque no querría que algunas de las demasiadas ocasiones que allí pueden ofrecerse me saltease la buena ventura que tanto me cuesta.

—Eso no, señor galán —respondió Preciosa-: sepa que conmigo ha de andar siempre la libertad desenfadada, sin que la ahogue ni turbe la pesadumbre de los celos [...]. Y mirad que los amantes que entran pidiendo celos, o son simples o confiados.

- Satanás tienes en tu pecho, muchacha — dijo a esta sazón la gitana vieja-: ¡mira que dices cosas que no las diría un colegial de Salamanca! Tú sabes de amor, tú sabes de celos, tú de confianzas: ¿cómo es esto?, que me tienes loca, y te estoy escuchando como a una persona espiritada, que habla latín sin saberlo.
Preciosa. Calle, abuela, y sepa que estas cosas que me oyen son muy pocas para las muchas que me quedan en el pecho. Si queréis ser mi esposo, yo lo seré vuestra, pero han de proceder algunas condiciones. Primero, tengo de saber si sois lo que decís: un caballero.

Juan. Mi nombre es Juan Cárcamo y mi padre está en la corte pretendiendo un cargo. Si algo más deseáis saber...

Preciosa. Una cosa me basta: la verdad. $Y$, en hallando esta verdad, habéis de dejar la casa de vuestros padres y la habéis de trocar con nuestros ranchos, tomando el traje de gitano...

Abuela. ¡Pero, muchacha, que es un caballero!

Preciosa. ¡Y yo soy gitana, abuela! Por gitano lo querré y no por caballero. (A Juan) Y habéis de cursar dos años en nuestros ranchos, en el cual tiempo me satisfaré yo de vuestra condición y vos de la mía.

Abuela. (Aparte) Veremos en qué para todo esto...

Preciosa. Si con estas condiciones, queréis entrar a ser soldado de nuestra milicia, en vuestra mano está. Volveos, señor, y considerad despacio a la que viereis que más os convenga y en este mismo lugar podréis hablarme todas las fiestas que quisiereis venir a Madrid.

Juan. Cuando el Cielo me 
-Calle, abuela — respondió Preciosa-, y sepa que todas las cosas que me oye son nonada, $y$ son de burlas, para las muchas que de más veras me quedan en el pecho. [...]

Sacó el mozo una bolsilla de brocado, donde dijo que iban cien escudos de oro, y dióselos a la vieja; pero no quería Preciosa que los tomase en ninguna manera, a quien la gitana dijo:

-Calla, niña, que la mejor señal que este señor ha dado de estar rendido es haber entregado las armas en señal de rendimiento; y el dar, en cualquiera ocasión que sea, siempre fue indicio de generoso pecho. $\mathrm{Y}$ acuérdate de aquel refrán que dice: "Al cielo rogando, y con el mazo dando". [...]. ¿Cien escudos quieres tú que deseche, Preciosa, y de oro en oro, que pueden andar cosidos en el alforza de una saya que no valga dos reales [...]? Y si alguno de nuestros hijos, nietos o parientes cayere, por alguna desgracia, en manos de la justicia, ¿habrá favor tan bueno que llegue a la oreja del juez y del escribano como destos escudos, si llegan a sus bolsas? [...].

—Por vida suya, abuela, que no diga más; que lleva término de alegar tantas leyes, en favor de quedarse con el dinero, que agote las de los emperadores: quédese con ellos, y buen provecho le ha- dispuso para quereros, Preciosa, determiné hacer por vos cuanto vuestra voluntad acertase a pedirme, aunque no cupo en mi pensamiento esto que ahora me pedís. Pues es ese vuestro gusto, que el mío al vuestro se acomode. Contadme por gitano, desde luego, $y$ haced por mí las experiencias que quisiereis. Ahí van los cien escudos de oro.

Preciosa. ¡No, abuela, no lo toméis de ninguna manera!

Abuela. Calla, niña, que la mejor señal que este señor ha dado en señal de rendimiento es entregar sus armas y el dar cualquier ocasión que sea indicio es de generoso pecho. $Y$ acuérdate del refrán que dice "A Dios rogando y con el mazo dando".

Preciosa. ¡Abuela!

Abuela. ¿Cien escudos quieres tú que deseche? Cien escudos que pueden andar cosidos en la alforza de una saya que no valga dos reales. Si alguno de nuestros hijos, nietos y demás parientes cayeren, por alguna desgracia, en mano de la justicia, ¿habrá razón tan buena que llegue a oreja del juez o del escribano como estos escudos?

JuAn. Por vida suya, abuela, que no diga más, que lleva a término de alegar tantas leyes a favor de quedarse con el dinero que...

Preciosa. Quédese con ellos y buen provecho le hagan. A esas, nuestras compañeras, forzoso será 
gan, [...]. A estas nuestras compañeras será forzoso darles algo, que ha mucho que nos esperan, $\mathrm{y}$ ya deben de estar enfadadas.

-Así verán ellas —replicó la vieja- moneda de estas, como ven al Turco agora. Este buen señor verá si le ha quedado alguna moneda de plata, o cuartos, y los repartirá entre ellas, que con poco quedarán contentas. darles algo, que ha mucho que nos esperan y deben estar enfadadas.

Abuela. Así verán ellas monedas de estas como ven al Turco ahora. (A Juan) ¿Os quedan alguna moneda de plata o cuartos para repartir entre ellas? (II, 3:14-11:40)

Vemos aquí cómo el primer parlamento de Cárcamo se divide en cuatro pequeñas alocuciones intercaladas con las de Preciosa: en la novela, Juan informa de su nombre y origen al principio; dos noticias que la serie relegaría a unos minutos después, como respuesta a las exigencias de Preciosa para subir al altar.

Por otro lado, en La gitanilla de Aguado, Juan le ruega que no vuelva a Madrid, oponiéndose al aparente rechazo de su amada, mientras que en el texto cervantino el galán le solicitaba este favor una vez aceptadas sus cláusulas. Nótese asimismo que la edad de la protagonista ha pasado de quince a veinte años para hacer más creíble la elección de la actriz Tina Sainz.

Por si fuera poco, se deslizan pequeños comentarios que no figuran en la novela ${ }^{35}$; algunos de los cuales contribuyen a definir los rasgos de los personajes televisivos: 1) cuando Juan la llama “amiga”, Preciosa le responde que ella no es tal; 2) la abuela, escandalizada por los términos en los que su nieta se dirige al noble, le advierte: "¡Pero, muchacha, que es un caballero!”; y ella la ataja de esta guisa: “YY yo soy gitana, abuela! Por gitano lo querré y no por caballero". Estas réplicas otorgan a Preciosa un carácter aún más fuerte y orgulloso que el de su homónima novelesca.

35 Según Francis Vanoye, Guiones modelo y modelos de guion, Barcelona, Paidós, 1996, p. 127, de la "necesidad de cortar y resumir, podría extrapolarse un modelo de adaptación entendida como reducción [...]. Pero esto es olvidar que la adaptación implica casi invariablemente las operaciones inversas: ańadidos, complementos y dilataciones, cosa que resulta evidente en las conversiones de textos breves en largometrajes". 
Sin abandonar estas secuencias, la abuela piensa en voz alta, a modo de aparte teatral, aquí señalado mediante un primer plano ${ }^{36}$. Percibimos entonces su inquietud ante la mentira ("Solamente un caballero admirara bajo estas prendas la distinción de una señora"; "Veremos en qué para todo esto..."), pues su nieta desconoce su linaje y Juan ha venido nada menos que a "levantar a la grandeza la humildad de Preciosa". La actitud de la anciana, suspicaz durante los cinco capítulos, compensa a las claras la elipsis del narrador en la reescritura. Me explicaré. Al comienzo de $L a$ gitanilla, Cervantes apuntaba que

Parece que los gitanos y gitanas solamente nacieron en el mundo para ser ladrones: nacen de padres ladrones, críanse con ladrones, estudian para ladrones y, finalmente, salen con ser ladrones corrientes y molientes a todo ruedo; y la gana del hurtar y el hurtar son en ellos como accidentes inseparables, que no se quitan sino con la muerte.

Una, pues, desta nación, gitana vieja, que podía ser jubilada en la ciencia de Caco, crio una muchacha en nombre de nieta suya, a quien puso nombre Preciosa, y a quien enseñó todas sus gitanerías y modos de embelecos y trazas de hurtar ${ }^{37}$.

Este íncipit, junto con la descripción de las virtudes de Preciosa, preparan al lector para la anagnórisis final. Así lo glosó El Saffar:

The dominance of the narrator over a plot whose peripeties are more complicated than they were in earlier works. The emphasis on the thieving of the gypsies and the many hints that Preciosa does not truly belong with the gypsies who brought her up prepare the reader for the final revelation of her noble birth ${ }^{38}$.

36 "La mayoría de los casos detectados en el teatro en televisión de apartes no presentan un plano general, sino que se aproximan hasta primeros planos o planos medios cortos, [gracias a los cuales] el sujeto de la enunciación fílmica se manifiesta intencionadamente por encima del enunciador escénico" (Pilar Espín Templado, "Pautas teórico-prácticas para el análisis semiótico de obras teatrales en televisión", en Del teatro al cine y la televisión en la segunda mitad del siglo XX, ed. José Romera Castillo, Madrid, Visor, 2002, pp. $561-570$ (p. 565)).

37 Cervantes, op. cit., p. 31.

38 Ruth El Saffar, Novel to Romance: A Study of Cervantes's "Novelas ejemplares", Baltimore / Londres, The John Hopkins University Press, 1974, p. 92. 
A falta de una voz extradiegética, serán las tribulaciones de la abuela las que nos permitan imaginar la alcurnia de la protagonista. Cuando en la novela Juan / Andrés proponía que escoltaran a Clemente hasta Sevilla, la vieja gitana se negaba a pisar dicha ciudad por temor a una broma que le gastó al gorrero Triguillos: encerrarlo hasta el cuello dentro de una tinaja. Un lance jocoso destinado a arrancar una sonrisa del lector. En cambio, en la cinta de TVE, visiblemente nerviosa, contará la anécdota para excusarse, habida cuenta de que los padres de Preciosa son los corregidores de Sevilla, y no de Murcia, como en el texto base. Puede que el cambio de marras obedeciera a la atmósfera picaresca que tradicionalmente se le ha asignado a la capital hispalense ${ }^{39}$, ya que los gitanos de la primera de las Ejemplares tienen mucho de rufianes ${ }^{40}$.

Durante resto del capítulo la abuela se mostrará siempre cabizbaja e incluso oiremos - por medio de una voz en off sobre un fondo de melancólicos violines_ sus miedos más ocultos: "Virgencita, no me la quites ahora, tan bonita y casadera, que como nieta la he tratado y nieta me ha de ser" (IV, 8:53).

39 Sevilla constituye el núcleo de la picaresca por excelencia, origen y cenit del Guzmán de Alfarache y sede de Rinconete y Cortadillo; una urbe que, según Luis Gómez Canseco, "La Sevilla odiada de Mateo Alemán", Minervae Baeticae. Boletín de la Real Academia Sevillana de Buenas Letras, XLI (2013), pp. 113-123 (p. 104), "se presenta como una miniatura perfecta de la maldad universal que Mateo Alemán dibujó en su libro, donde solo el dinero, la mentira y el interés propio actúan como causa y motor con que justificar el avieso comportamiento de los personajes". En efecto, como explicara Héctor Brioso Santos, Sevilla en la prosa de ficción del Siglo de Oro, Sevilla, Diputación de Sevilla, 1998, p. 104, la capital andaluza aparece con frecuencia relacionada en las letras con el interés económico y el lujo, despertando "la codicia de los que, no poseyendo medios suficientes, desean tener parte en el reparto social".

40 De acuerdo con Avalle-Arce, op. cit., p. 22, "para el lector del siglo XviI La gitanilla tiene arranque de novela picaresca. Y todo esto lo cohonesta la calidad de los personajes (gitanos-ladrones), el ambiente urbano (la picaresca no se puede desempeñar en ambiente rural), fiestas y refocilaciones”. En opinión de Sevilla Arroyo y Rey Hazas, $o p$. cit., p. XLIX, esta historia "tiene elementos dispares procedentes de la novela pastoril y de la bizantina, sobre todo, y en mucho menor medida de la picaresca". Finalmente, Stanislav Zimic, Las "Novelas ejemplares" de Cervantes, Madrid, Siglo XxI, 1996, p. 31, compara a los gitanos con los pícaros de Monipodio, ante los cuales "el lector adopta una actitud de indulgente ironía más que de indignación moral frente a este mundo, que, por ignorancia y cierta ingenuidad, pese a toda su reclamada agudeza, se revela tan convencido de estar haciendo el bien cuando hace el mal". 


\subsection{Poemas de quita y pon}

Los diálogos no fueron los únicos apuros que Rubio y Romá hubieron de sortear. Como recuerda Clamurro, "the number, variety, and complexity of the poems found in La gitanilla distinguish it from the other novelas of the collection"41. Por un lado, no resultaba viable incluir todos los versos, que hubieran cansado al público de Novela; por otro, desperdiciar la oportunidad de incluir tan pintorescos interludios, que daban pie a los bailes de los gitanos, habría sido una verdadera pena. De nuevo, la solución pasaba por cortar y reorganizar. Aunque esta vez los guionistas no salieron tan airosos.

En La gitanilla de Cervantes hallamos ocho composiciones ${ }^{42}$ : cuatro romances - "Árbol preciosísimo" (1), "Salió a misa de parida" (2), "Gitanica, que de hermosa" (3) y el de la buenaventura: "Hermosita, hermosita" (4)-, el soneto "Cuando Preciosa la pandereta toca" (5), la redondilla seguida de una tirada de octosílabos y tetrasílabos en pareado "Cabecita, cabecita" (6) y, por fin, el diálogo en silvas entre Clemente y Juan (7), al cual responden unas redondillas de Preciosa (8).

No son pocos los que han reparado en la importancia de este cancionerillo para la recta comprensión del relato. Forcione fue uno de los pioneros: "The poems in the early part of the tale [...] can be understood as carefully integrated emblematic statements of its principal themes" 33 .

41 Clamurro, "Enchantment and Irony", p. 76.

42 El doble que en La ilustre fregona (la que la sigue más de cerca), y muy lejos ya de $E l$ amante liberal, Rinconete y Cortadillo, El celoso extremeño y El coloquio de los perros, las cuatro con un solo poema.

43 Alban K. Forcione, Cervantes and the Humanist Vision: a Study of Four Exemplary Novels, Princeton, Princeton University, 1982, p. 136. Karl-Ludwig Selig, "Concerning the Structure of Cervantes' La gitanilla", Romanistisches Jahrbuch, XIII, 1 (1962), pp. 273-276, también lo puso de relieve: "Poetry, and subordinated to it, the individual poem, function dramatically throughout the work. The poetry moves us from scene to scene. We have a series of scenes, each scene made more meaningful in its association with poetry or a poem" (p. 272). George Güntert, "La gitanilla y la poética de Cervantes”, Boletín de la Real Academia Española, LII (1972), pp. 107-134, añadiría que "los versos en La gitanilla no tienen el valor decorativo que les adjudica el pensamiento de casi todos los críticos. Especialmente los dos 
El romance con el que Preciosa debuta como rapsoda es "Árbol preciosísimo", en honor a santa Ana en el día de su festividad. Sin embargo, los primeros versos que oyó la audiencia de TVE pertenecían al segundo romance del original: "Salió a misa de parida" ${ }^{4}$. La diferencia estriba en que en la novelita cantaba estas dos composiciones en Madrid, pero en dos ocasiones distintas. Rubio y Romá optaron por fusionarlas, dejando así espacio para uno solo de los romances. El elegido fue "Árbol preciosísimo", por más que no quisieran desechar del todo el segundo, ya que Tina Sainz lo recita en voice over durante los créditos -impresos sobre unas cartulinas que presentan a los personajes, de forma parecida a las xilografías de los incunables (por ejemplo, las de la edición valenciana de La Celestina, 1514; Fig. 1) — que abren el primer capítulo (Figs. 2-3).

romances del principio contienen ya la temática fundamental de la novela. El primero, cantado delante de una imagen de santa Ana el día de su fiesta, no exulta solamente la maternidad, como cree Casalduero, sino que ostenta una profunda analogía con un aspecto central de la novela: la poesía" (p. 128). En cambio, Carroll B. Johnson, "De economías y linajes en La gitanilla", Mester, xxv, 1 (1996), pp. 31-48, defiende la visión matriarcal del linaje en los poemas dedicados a santa Ana, la reina Margarita y dońa Clara: "Lo que este texto propone es una genealogía matrilineal. Preciosa misma al principio pertenece a un matrilinaje, definido por ella y su abuela. El linaje de dońa Clara, mujer del teniente, empieza en ella. El linaje del futuro Felipe IV aparece en el texto como obra de su madre. El linaje de Jesús es también un matrilinaje, de santa Ana pasando por María. Una y otra vez asistimos a la marginación, cuando no la exclusión, del padre" (p. 46). Ver también Monique Joly, "En torno a las antologías poéticas de La gitanilla y La ilustre fregona", Cervantes: Bulletin of the Cervantes Society of America, XIII, 2 (1993), pp. 5-15.

44 Avalle-Arce, op. cit., p. 80, n. 25; García López, op. cit., pp. 34-35, n. 47; y Alberto Blecua, "Cervantes y su intertextualidad española", en "El robo que robaste": el universo de las citas y Miguel de Cervantes [monográfico], ed. Aurora Egido, Parole rubate: Rivista internazionale di studi sulla citazione, viII (2013), pp. 197-219 (p. 217), ya advirtieron el origen de esta composición en un romance del Cid ("De cómo Jimena Gómez, estando el Cid ausente, parió y salió a misa, y cómo el rey la tomó en el camino y la acompañó hasta la iglesia y a su casa la volvió"); vínculo que unos años después repetiría Adrián J. Sáez, "El Cid de Cervantes: dos romances de La gitanilla y La entretenida”, Etiópicas, XIV (2018), pp. 37-49. 


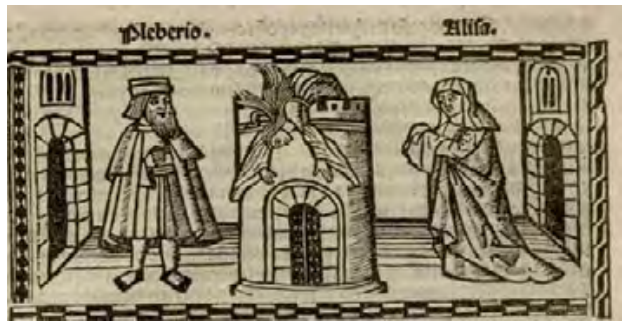

Fig. 1

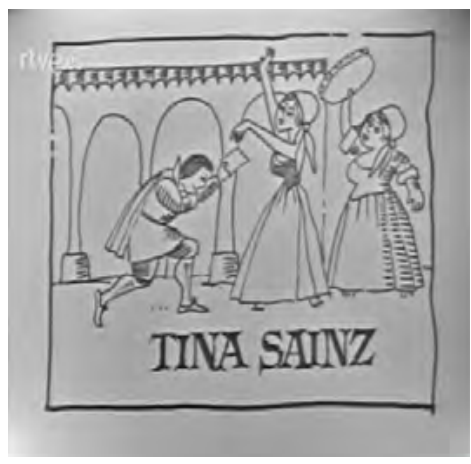

Fig. 2

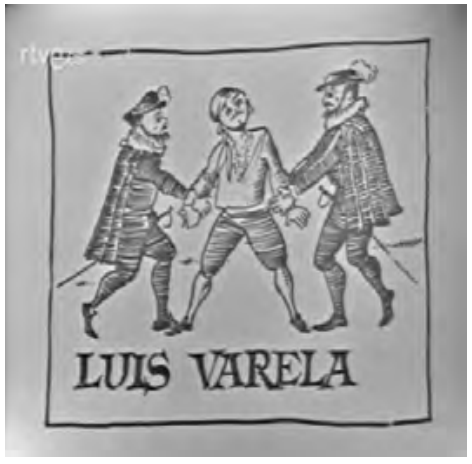

Fig. 3

Nótese asimismo que los 128 versos del original se redujeron a 12:

Salió a misa de parida la mayor reina de Europa, en el valor y en el nombre rica y admirable joya.

A sus espaldas la sigue un Lucero que a deshora salió, la noche del día que el cielo y la tierra lloran. Y si en el cielo hay estrellas que lucientes carros forman en otros carros su cielo vivas estrellas adornan (I, 00:46). 
El sentido del romance sufre aquí un cambio drástico. Si en la novela se trataba de una extensa alegoría sobre la reina Margarita de Austria, esposa de Felipe III, el espectador habrá de aplicar a Preciosa las palabras que Cervantes escribió para la soberana, si bien prescindiendo de no pocas imágenes. Por ejemplo, "el Lucero" del v. 6, referido al futuro Felipe IV, no funciona en este nuevo contexto.

Pero el poema no solo aparece recortado sino también desordenado, según la costumbre de los guionistas en su reescritura: la cita anterior recoge los vv. 1-4 y 13-20. Se podría juzgar como un acierto la ausencia de los cuartetes intermedios —donde asomaban referencias a los Habsburgo ("a un lado lleva el sol de Austria / al otro, la tierna aurora”, vv. 11 y 12)—, si no fuera porque aparecerán un capítulo más tarde, puestos esta vez en boca de la abuela (II, 12:00). Mutilado y fuera de contexto, el romance se torna superfluo.

Por otro lado, al lector de La gitanilla le chocará que sea la vieja quien lo declame, ya que Preciosa es la única voz femenina que canta dentro de la novela, lo que induce a identificarla con la misma poesía, en virtud de la definición de esta última a cargo del paje-poeta ${ }^{45}$ :

Hase de usar de la poesía como de una joya preciosísima, cuyo dueño no la trae cada día, ni la muestra a todas gentes, ni a cada paso, sino cuando convenga y sea razón que la muestre. La poesía es una bellísima doncella, casta, honesta, discreta, aguda, retirada, y que se contiene en los límites de la discreción más alta. Es amiga de la soledad, las fuentes la entretienen, los prados la consuelan, los árboles la desenojan, las flores la alegran, y, finalmente, deleita y enseńa a cuantos con ella comunican ${ }^{46}$.

45 "Cervantes, al mismo tiempo que hace de Preciosa la forma, la figura de una idea platónica, de la honestidad, nos describe la Poesía en La gitanilla exactamente con las mismas palabras con que ha dado ser a Preciosa" (Joaquín Casalduero, Sentido y forma de las "Novelas ejemplares", Madrid, Gredos, 1969, p. 77); "Preciosa, en quien concurren todas estas cualidades, tiene que simbolizar la poesía misma, joya exiliada, hemos dicho, en un mundo que con su presencia embellece" (Güntert, op. cit., p. 124); "Las palabras que le dirige el paje cuando le da el segundo soneto son reveladoras, pues permiten ver en la gitanilla ilustre un símbolo de la poesía" (Sevilla Arroyo y Rey Hazas, op. cit., p. XLv); "The performance of poetry is a vital part of what Preciosa is or is made to represent" (William H. Clamurro, Beneath the Fiction. The Contrary Worlds of Cervantes's "Novelas ejemplares", Nueva York, Peter Lang, 1997, pp. 31-32). Ver, asimismo, Forcione, op. cit., pp. 215-222.

46 Cervantes, op. cit., p. 63. 
Por consiguiente, la adaptación cancela el monopolio versificador de Preciosa y, con él, la metáfora que la erigía en personificación de la lírica.

Más extraño aún se antoja que al recitar "Árbol preciosísimo", lo anuncie como un romancillo en honor de la reina Margarita, pues en realidad se cifra en la figura de santa $\mathrm{Ana}^{47}$. Nótese una vez más la severa poda y el no menos confuso discurso:

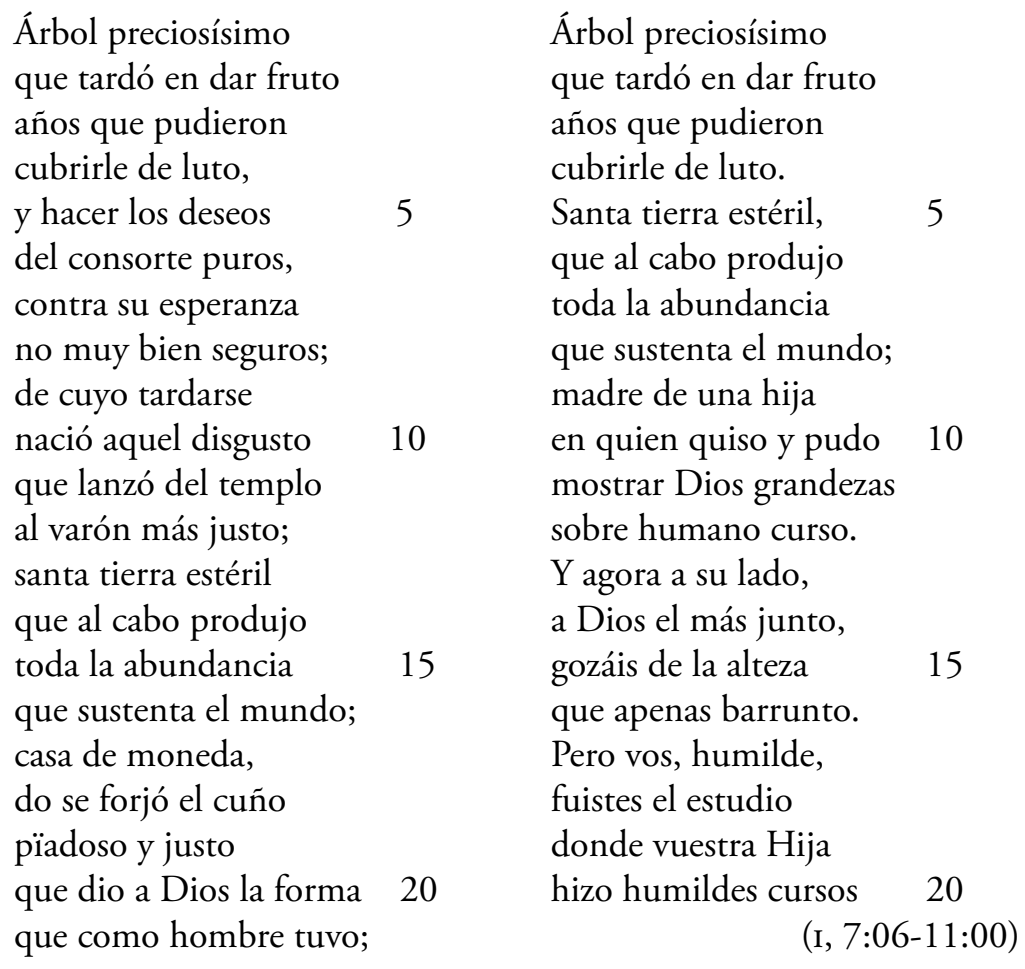

47 "In the Romance de Santa Ana, which Rodríguez Marín erroneously labels an 'empanada teológico-poética de [...] escaso mérito' (ed. cit., p. 8, n. 19), Cervantes underlines the possibility of the existence of spiritual nobility amidst rustic simplicity" (E. Michael Gerli, "Idealism and Irony in La gitanilla", Cervantes: Bulletin of the Cervantes Society of America, vi, 1 (1986), pp. 29-38 (p. 35)). En opinión de Ruth Fine, "De inversiones e ironías: La gitanilla y El amante liberal en clave bíblica”, Anales cervantinos, xLVIII (2016), pp. 377-386 (p. 379), asoman en este poema evocaciones del imaginario del Génesis: "la creación del hombre a imagen de Dios, el jardín edénico y sus emblemáticos árbol y fruto, como también la referencia al justo varón (Noé, Génesis 6: 9)”. 
madre de una hija en quien quiso y pudo mostrar Dios grandezas sobre humano curso.

Por vos y por ella sois, Ana, el refugio do van por remedio nuestros infortunios. En cierta manera, tenéis, no lo dudo, sobre el Nieto, imperio pïadoso y justo.

A ser comunera del alcázar sumo,

fueran mil parientes con vos de consuno. ¡Qué hija, y qué nieto, y qué yerno! Al punto, a ser causa justa, 40 cantárades triunfos. Pero vos, humilde, fuistes el estudio donde vuestra Hija hizo humildes cursos; y agora a su lado, a Dios el más junto, gozáis de la alteza que apenas barrunto.

Los vv. 45-48 se anteponen al cuartete previo en Cervantes (vv. 41-44), problematizando la oración adversativa "Pero, vos, humilde, / fuiste el estudio / donde vuestra Hija / hizo humildes cursos" 48 . Y para más inri, los vv. 14-25 se repetirán en los créditos del quinto episodio.

48 Se hace imposible determinar la razón de este trueque: bien podría deberse a una decisión premeditada de los guionistas, a un descuido en la transcripción o quizá a un desliz de Tina Sainz. Una cosa queda clara: ni los unos ni la otra -y lo mismo se puede afirmar del realizador - se esforzaron por captar el significado de los poemas cervantinos; de ahí que aparezcan desarmados y recompuestos a capricho. 
Las cabeceras de los capítulos segundo, cuarto y quinto se repartirán las redondillas de "En esta empresa amorosa", la réplica que Preciosa daba a las silvas entonadas por Clemente y Juan en la novela ${ }^{49}$. Este diálogo, de clara naturaleza bucólica, desaparecería, por cierto, en la versión de TVE ${ }^{50}$. Según Clamurro, Cervantes evocaba con dicho episodio "the mood and expectations of the pastoral tradition more than any other part of this novela". Además, en él se atenúa la distinción entre los dos hombres: "In the act of poetry, and perhaps through the power of poetry, the mysterious Clemente and the temporary gypsy Andrés become a single voice" ${ }^{2}$. Nada de esto sobrevive en La gitanilla de Manuel Aguado. Es más, la relación entre los jóvenes distará mucho de la complicidad idealista que dibujó el complutense.

Uno de los romances más comentados ha sido el de la buenaventura de Preciosa a doña Clara, la mujer del teniente. Márquez Villanueva le consagró un fino estudio al que "cabría calificar como enfant terrible de los poemas cervantinos" 52 y "una de las claves fundamentales para el lector inteligente de La gitanilla" ${ }^{3}$. Helo aquí:

49 Según García López, op. cit., p. 846, "Cervantes parece condensar y resumir [aquí] el carácter de Preciosa, reivindicando la libertad individual y la esencial igualdad humana. Poema lleno de platonismo y 'feminismo' en abierto contraste con la supuesta ideología estamental de la narración, y más concretamente, con el poema dedicado a Santa Ana”.

50 José Montero Reguera, "La gitanilla: una reivindicación de la poesía", Ínsula, DCCXCIX-DCCC (2013), pp. 34-36, señala que las redondillas de la respuesta de Preciosa "presentan una importancia destacada en el acontecer de la narración, pues sugieren el final feliz esperable al justificar la posibilidad de un amor desigual" (p. 36).

51 Clamurro, Beneath the Fiction, p. 28.

52 Francisco Márquez Villanueva, "La buenaventura de Preciosa", Nueva Revista de Filología Hispánica, xxIv (1985), pp. 741-768 (p. 743).

53 Ibidem, p. 745. Antes que Márquez Villanueva, se detuvieron en él Julio RodríguezLuis, Novedad y ejemplo de las novelas de Cervantes, Madrid, tomo I, José Porrúa, 1984, p. 114) y Forcione, op. cit., p. 138: "Here we discover a marriage in which both partners exhibit a good deal of violence and lust, frequently scold and beat one another, and appear to be yoked until death in a conjugal relationship plagued by tyranny, fear, jealousy and adultery". También Bénédicte Torres, "La poesía en La gitanilla: ¿Es preciosa 'algo desenvuelta, pero no de modo que descubriese algún género de deshonestidad'?", Hesperia. Anuario de Filología Hispánica, xxi, 2 (2018), pp. 133-150) señala al respecto que "la desenvoltura de Preciosa se manifiesta 
Hermosita, hermosita, la de las manos de plata, más te quiere tu marido que el Rey de las Alpujarras.

Eres paloma sin hiel, pero a veces eres brava como leona de Orán, o como tigre de Ocańa.

Pero en un tras, en un tris, el enojo se te pasa, y quedas como alfinique, o como cordera mansa.

Riñes mucho y comes poco: algo celosita andas; que es juguetón el tiniente, y quiere arrimar la vara.

Cuando doncella, te quiso uno de una buena cara; que mal hayan los terceros, que los gustos desbaratan.

Si a dicha tú fueras monja, hoy tu convento mandaras, porque tienes de abadesa más de cuatrocientas rayas.

No te lo quiero decir...; pero poco importa, vaya: enviudarás, y otra vez, y otras dos, serás casada.

No llores, señora mía; que no siempre las gitanas decimos el Evangelio; no llores, señora, acaba.

Como te mueras primero que el señor tiniente, basta para remediar el dańo

ante todo en la poesía, su honestidad tantas veces proclamada le da una libertad extraordinaria para denunciar la deshonestidad que encarnan el teniente y su mujer doña Clara” (p. 147). 
de la viudez que amenaza.

Has de heredar, y muy presto, hacienda en mucha abundancia; tendrás un hijo canónigo, la iglesia no se señala:

de Toledo no es posible.

Una hija rubia y blanca tendrás, que si es religiosa, también vendrá a ser perlada.

$\mathrm{Si}$ tu esposo no se muere dentro de cuatro semanas, verasle corregidor de Burgos o Salamanca.

Un lunar tienes, ¡qué lindo! ¡Ay Jesús, qué luna clara! ¡Qué sol, que allá en los antípodas 50 escuros valles aclara!

Más de dos ciegos por verle dieran más de cuatro blancas. ¡Agora sí es la risica! ¡Ay, que bien haya esa gracia!

Guárdate de las caídas, principalmente de espaldas, que suelen ser peligrosas en las principales damas.

Cosas hay más que decirte; si para el viernes me aguardas, las oirás, que son de gusto, $\mathrm{y}$ algunas hay de desgracias ${ }^{54}$. 
y hasta las lacras de la misma sangre ${ }^{55}$.

Nos hallamos ante la pequeña venganza de la gitanilla tras percatarse de que los nobles no están dispuestos a pagarle por sus servicios. Y a su vez, se trata de uno de los pasajes más críticos del texto, dado que pone sobre la mesa la hipocresía de las clases pudientes. Sin embargo, en la serie de Aguado, Preciosa solo recitará los cuatro primeros versos, dando por ello al traste con el hiriente propósito de su homónima novelesca.

\section{EL IDEALISMO POR EL IDEALISMO}

La gitanilla se debate de principio a fin entre el idealismo y el realismo. El primero viene determinado por la descripción de los gitanos, que, alejados de las ciudades, se desenvuelven en la bucólica naturaleza, de modo que "muchos de sus rasgos definidores proceden de los pastores idealizados [por] la tradición" 56 . Güntert adelantó que este mundo, tal como lo describe Cervantes, "tiene poco que ver con una descripción realista, [puesto que] recuerda con insistencia el topos [...] de la Edad de Oro" ${ }^{57}$. Tanto es así que Forcione concluiría que "it is tempting to see the Gypsy community as a realm of essential values, a type of 'green world', which exposes by contrast the deficiencies of the real world and points toward the ideals that are to be impressed on reality if purification is to occur" ${ }^{\prime 5}$. Todo ello saldrá a relucir en el discurso del viejo gitano:

Con estas y con otras leyes y estatutos nos conservamos y vivimos alegres; somos seńores de los campos, de los sembrados, de las selvas, de los montes, de las fuentes y de los ríos. Los montes nos ofrecen leña de balde; los árboles, frutas; las viñas, uvas; las huertas, hortaliza; las fuentes, agua; los ríos, peces, y los vedados, caza; sombra, las peñas; aire fresco, las quiebras; y casas, las cuevas. Para nosotros las inclemencias del cielo son oreos, refrigerio las nieves, baños la llu-

55 Márquez Villanueva, op. cit., p. 750.

56 Sevilla Arroyo y Rey Hazas, op. cit., p. xxiv.

57 Güntert, op. cit., pp. 113-114.

58 Forcione, op. cit., pp. 187-188. 
via, músicas los truenos y hachas los relámpagos. Para nosotros son los duros terreros colchones de blandas plumas: el cuero curtido de nuestros cuerpos nos sirve de arnés impenetrable que nos defiende; a nuestra ligereza no la impiden grillos, ni la detienen barrancos, ni la contrastan paredes; a nuestro ánimo no le tuercen cordeles, ni le menoscaban garruchas, ni le ahogan tocas, ni le doman potros. [...]. Por dorados techos y suntuosos palacios estimamos estas barracas y movibles ranchos; por cuadros y países de Flandes, los que nos da la naturaleza en esos levantados riscos y nevadas peńas, tendidos prados y espesos bosques que a cada paso a los ojos se nos muestran. Somos astrólogos rústicos, porque, como casi siempre dormimos al cielo descubierto, a todas horas sabemos las que son del día y las que son de la noche; vemos cómo arrincona y barre la aurora las estrellas del cielo, y cómo ella sale con su compañera el alba, alegrando el aire, enfriando el agua y humedeciendo la tierra; y luego, tras ellas, el sol, dorando cumbres (como dijo el otro poeta) y rizando montes: ni tememos quedar helados por su ausencia cuando nos hiere a soslayo con sus rayos, ni quedar abrasados cuando con ellos particularmente nos toca; un mismo rostro hacemos al sol que al yelo, a la esterilidad que a la abundancia. En conclusión, somos gente que vivimos por nuestra industria y pico, y sin entremeternos con el antiguo refrán: "Iglesia o mar o casa real"; tenemos lo que queremos, pues nos contentamos con lo que tenemos ${ }^{59}$.

Sevilla Arroyo y Rey Hazas explicaron que, dado el antigitanismo que imperaba en el Madrid de principios del XVII —desde 1609 a 1613 se sancionaron órdenes de expulsión-, la novela tuvo que impactar a los lectores de la época, "que esperarían cualquier cosa menos una idealización de los gitanos" ${ }^{60}$. Luego Cervantes reaccionaba así contra las prácticas racistas de su tiempo. Además,

que Preciosa sea gitana exige una reflexión sobre el alcance de esa elección literaria, puesto que no deja de ser un hecho hasta cierto punto insólito y no exento de una profunda originalidad. Los gitanos están ausentes de tradición literaria y, además, el tratamiento literario de una minoría social incidía sobre la definición de las ideas

59 Cervantes, op. cit., pp. 75-77.

60 Sevilla Arroyo y Rey Hazas, op. cit., pp. XxIx-Xxx. 
de Cervantes al respecto; en fin, cabe interrogarse sobre el uso del tema en el decurso del relato ${ }^{61}$.

Es obvio que la pragmática varía en la versión televisiva. En primer lugar, el idealismo que los rodea carece del potencial subversivo del texto: los calés que contempla el público de Novela de ningún modo se identifican con los de los años setenta; y tampoco con los de nuestros días. A la idealización operada por el alcalaíno se suma la del paso del tiempo. No solo porque difícilmente los gitanos del Barroco eran tal y como nos los pintan en el capítulo. Considérese que este retrato deriva en paralelo de una tradición romántica que arranca de la novela cervantina y culmina en el Romancero gitano (1928) de García Lorca, pasando por Pushkin (Los cíngaros, 1824), la Carmen (1847) de Mérimée y la famosa ópera de Bizet (1875). Y tampoco se orillen, ya dentro del séptimo arte, espańoladas como Morena clara (Florián Rey, 1936), Carmen, la de Triana (Florián Rey, 1938) o la versión de La gitanilla de Rafael Gil (Fernando Delgado, 1940), hoy perdida ${ }^{62}$.

En otro orden de cosas, si la visión del viejo gitano evoca el mito de la Edad de Oro, ya sublimado por don Quijote en el capítulo XI de la segunda parte de la novela ${ }^{63}$, cabe reparar también en la importancia que el campo cobra dentro de las narraciones de Rodrigo Rubio:

[Su mundo literario] aparece agrupado en torno a tres grandes ejes

61 García López, op. cit., p. 830.

62 José Luis Navarrete Cardero, "La españolada y Sevilla", Cuadernos de Eihceroa, IV (2003), pp. 9-67, define la “españolada” como "género literario, pictórico, musical y, finalmente, cinematográfico, entroncado con el siglo xvi español. Los personajes [...] y tramas que lo conforman ya aparecen en las manifestaciones artísticas españolas [...] desde el Seiscientos. Sin embargo, el proceso de etiquetaje [...] se debe a los románticos europeos, especialmente a los franceses con la creación del término espagnolade. [...] Este solo ha puesto nombre a un conjunto de manifestaciones y gustos populares: 'gitanización', 'andalucismo', bravuconadas de jaques, torerías, supersticiones, sensualidad, danzas flamencas y sucedáneas, hechicerías, y una larga lista de elementos presentes desde siempre en la vena popular de las artes espańolas" (pp. 10-11).

63 Ver Giuseppe Mazzocchi, Molto sono le strade. Spiritualità, mistica e letteratura nella Spagna dei secoli d'oro (con un'appendice novecentesca), Nápoles, Liguori, 2018 pp. $125-144$. 
narrativos. En primer lugar, el de la ańoranza del mundo perdido, el de la vida del campo manchego, que permanentemente está presente en su proustiano retorno al pasado. Un eje narrativo que [...] aparece en sus primeras obras y que, cual pescadilla que se muerde la cola, [resucita] en muchos de sus últimos escritos ${ }^{64}$.

Dicho esto, queda claro que los cíngaros de La gitanilla de TVE poco tenían que ver con el espíritu subversivo de la novela. Y por desgracia tampoco conservaron su encanto. Si en el texto base "el trazo afirmativo y vigoroso con que está captada la figura de Preciosa se impuso inmediatamente a la imaginación de los lectores" ${ }^{35}$, la serie de Aguado anduvo lejos de emularlo. A causa, en esencia, del formato de las producciones dramáticas de entonces: grabaciones en estudio, bajo presupuesto, escenografía teatral. Con todo, su esfuerzo resulta loable, sobre todo al recrear plazas, mesones, casas solariegas e incluso un aduar.

Constituye todo un acierto la apuesta por extras gitanos que tocan las palmas para dotar de empaque a los bailes que abren o cierran los cinco capítulos. Sin embargo, la abundancia de este tipo de escenas incide en la lectura costumbrista. Además, frente a la hipnótica Preciosa cervantina, la televisiva, ataviada con una artificial peluca rubia - muy alejada de la imagen habitual de Tina Sainz_- no baila ni recita como para lanzar las campanas al vuelo. Y si en la novela Preciosa destacaba entre los gitanos por su piel clara y cabellos dorados, los responsables de Novela escogieron a una paya (María José Hernández) para encarnar a la gitana Cristina, que también desentona dentro del clan.

Al margen de estas licencias, Aguado tampoco supo aprovechar las posibilidades expresivas de la cámara. Sus planos son esclavos del teatro: generales en su mayoría, medios para los diálogos y cortos en los discursos o apartes. Con una excepción: durante los bailes, el realizador se recrea en la escenografía por medio de lentos travellings circulares. Un indicio más del espíritu "sainetesco" de la cinta (Figs. 4-5) ${ }^{66}$.

64 Manuel Cifo González, "Aproximación didáctica a Rodrigo Rubio: un escritor entre la realidad y el deseo", Al-basit. Revista de Estudios Albacetenses, LIII (2009), pp. 289-308 (p. 294).

65 Casalduero, op. cit., p. 56.

66 Ver Juan A. Ríos Carratalá, Lo sainetesco en el cine español, Alicante, Universidad de Alicante, 1997. 


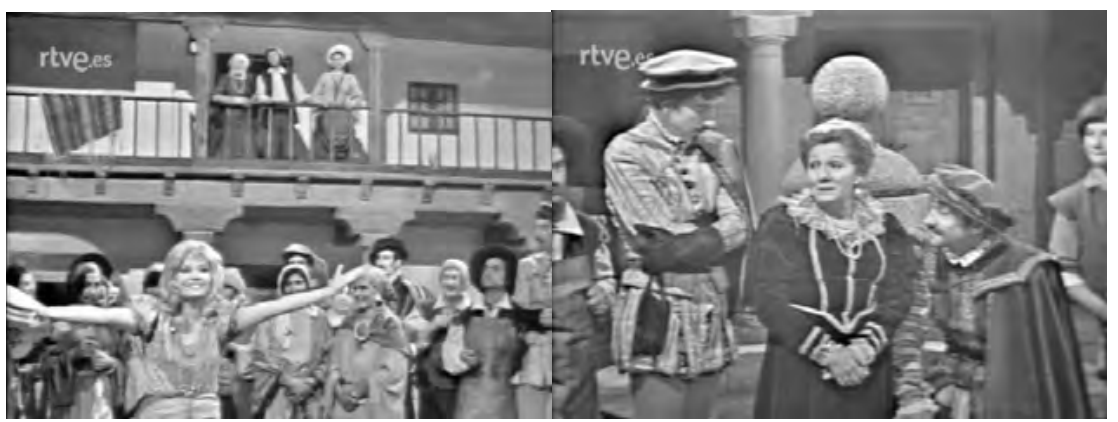

Fig. 4

Fig. 5

\subsection{Gitanos ideales y gitanos salvajes}

De vuelta al discurso del viejo gitano, que describía su existencia como libre de ataduras y hermanada con la naturaleza, conviene no ocultar los defectos de una comunidad incivilizada, sobre todo en lo relativo al trato de la mujer:

Esta muchacha, que es la flor y la nata de toda la hermosura de las gitanas que sabemos que viven en España, te la entregamos, ya por esposa o ya por amiga, que en esto puedes hacer lo que fuere más de tu gusto, porque la libre y ancha vida nuestra no está sujeta a melindres ni a muchas ceremonias. [...] Pero has de saber que una vez escogida, no la has de dejar por otra, ni te has de empachar ni entremeter, ni con las casadas ni con las doncellas. Nosotros guardamos inviolablemente la ley de la amistad: ninguno solicita la prenda del otro; libres vivimos de la amarga pestilencia de los celos. Entre nosotros, aunque hay muchos incestos, no hay ningún adulterio; $\mathrm{y}$, cuando le hay en la mujer propia, o alguna bellaquería en la amiga, no vamos a la justicia a pedir castigo: nosotros somos los jueces y los verdugos de nuestras esposas o amigas; con la misma facilidad las matamos, y las enterramos por las montañas y desiertos, como si fueran animales nocivos; no hay pariente que las vengue, ni padres que nos pidan su muerte. Con este temor y miedo ellas procuran ser castas, y nosotros, como ya he dicho, vivimos seguros. [...] Entre nosotros así hace divorcio la vejez como la muerte; el que quisiere 
puede dejar la mujer vieja, como él sea mozo, y escoger otra que corresponda al gusto de sus años ${ }^{67}$.

Lejos de idealizarlos, Cervantes refuta ahora "el deseo romántico de recrear una primitiva Edad de Oro, donde el hombre pueda vivir en su virtuosa armonía"68. Es precisamente la unión entre lo bucólico y lo salvaje la que crea el doblez que "ofrece a nuestra mirada una óptica compleja, a la vez que utópica e irónica, de la vida gitana, al mismo tiempo idealizada y realista"69.

Así se abocetó en el tercer capítulo de TVE el monólogo que acabo de transcribir:

Esta gitanilla, que es la flor y nata de las gitanillas, te la entregamos como esposa. Mírala bien y mira si te agrada o ves en ella alguna cosa que te descontente, pues has de saber que, una vez escogida, no la has de cambiar por otra. Nosotros guardamos inviolablemente la ley de la amistad. Ninguno solicita la prenda del otro, libres y exentos estamos de la amarga pestilencia de los celos. Un mismo rostro le hacemos al sol que al hielo, a la esterilidad que a la abundancia. Somos gentes de nuestra industria y pico. Sin entrometernos en el antiguo refrán de iglesia o mar o casa real. Tenemos lo que queremos, pues nos contentamos con lo que tenemos (III, 7:30).

Al comparar ambos textos, salta a la vista que se han eliminado en la adaptación aquellos trazos que ensombrecían la ideal Arcadia gitana: los cíngaros de Aguado no cometen incesto, ni abandonan a sus esposas por otras más jóvenes, ni tampoco las matan si ellas les pagan con la misma moneda. En su lugar, se respetan los unos a los otros, huyen de los celos y se guardan fidelidad, a pesar de los obstáculos. En vez de representar a una cáfila marginal, casi podrían servir de ejemplo para los señores de la corte. Tampoco los veremos robar — atributo clave en los de Cervantesy las noticias sobre "su industria" son escasas.

67 Cervantes, op. cit., p. 75.

68 Peter Dunn, "Novelas ejemplares", en Suma cervantina, eds. Juan Bautista AvalleArce y Edward C. Riley, Londres, Támesis, 1973, pp. 81-118 (p. 75). Ver asimismo Zimic, op. cit., pp. 13-18.

69 Sevilla Arroyo y Rey Hazas, op. cit., p. XXviI. 
Sorprende que la réplica de Preciosa a las palabras del viejo mengüe en la serie, perdiendo buena parte de su irreverencia ${ }^{70}$ :

Puesto que estos señores legisladores han hallado por sus leyes que soy tuya, y que por tuya te me han entregado, yo he hallado por la ley de mi voluntad, que es la más fuerte de todas, que no quiero serlo si no es con las condiciones que antes que aquí vinieses entre los dos concertamos. Dos años has de vivir en nuestra compañía [primero que de la mía goces,] porque tú no te arrepientas por ligero, ni yo quede engañada por presurosa. [Condiciones rompen leyes; las que te he puesto sabes: si las quisieres guardar, podrá ser que sea tuya y tú seas mío; y donde no, aún no es muerta la mula, tus vestidos están enteros, y de tus dineros no te falta un ardite; la ausencia que has hecho no ha sido aún de un día; que de lo que de él falta te puedes servir y dar lugar que consideres lo que más te conviene. Estos señores bien pueden entregarte mi cuerpo; pero no mi alma, que es libre y nació libre, y ha de ser libre en tanto que yo quisiere. [...]; no querría yo que fueses tú para conmigo como es el cazador, que, en alcanzado la liebre que sigue, la coge y la deja por correr tras otra que le huye. [...] Que yo no me rijo por la bárbara e insolente licencia que estos mis parientes se han tomado de dejar las mujeres, o castigarlas, cuando se les antoja; y, como yo no pienso hacer cosa que llame al castigo, no quiero tomar compañía que por su gusto me deseche $]^{71}$.

La ambigüedad desaparece del todo en el guion de Rubio y Romá, que arrebatan a los gitanos las cualidades que los distinguían de los poderosos, en tanto que comunidad ajena a las normas sociales y a la justicia ordinaria. Lo cierto es que "la visión descarnada y negativa de los gitanos era, al menos, tan imprescindible para sus propósitos como la idealizada"72. Al borrar esta perspectiva jánica, el relato de Manuel Aguado se empobrece, inclinándose de nuevo hacia un costumbrismo algo maniqueo.

70 Entre corchetes los pasajes eliminados en la adaptación (III, 10:40).

71 Cervantes, op. cit., pp. 78-79.

72 Sevilla Arroyo y Rey Hazas, op. cit., p. XXvir. 
Clemente — también conocido como Alonso y Sancho ${ }^{73}$ —, el paje-poeta, es uno de los personajes más enigmáticos del relato:

As a character, the page-poet remains totally undefined: he appears at night, apparently from nowhere and without being able to state a convincing destination. In Madrid he had described himself as a poet and yet not one, as neither rich nor poor, as a page and yet more than that $^{74}$.

No obstante, desempeña "una función esencial en la estructura de la novela, pese a que algunos le concedan un papel meramente decorativo"75. Nadie lo ha diseccionado mejor que Clamurro, quien lo relaciona con Juan/Andrés: ambos actúan al alimón para dar jaque a la justicia de la sociedad más "ortodoxa”. En este sentido, la singularidad de Clemente no radica en su caracterización como poeta, sino en la historia sobre su pasado. Recordemos que el paje le cuenta a Andrés que las autoridades lo persiguen por el asesinato de dos seńores principales que para socorrer a un amigo cometió en defensa propia. Lo cual no evitará que Clemente se vea obligado a escapar y, en medio de su fuga, se tope con el aduar de Preciosa.

El caso de Juan / Andrés representa la cruz de la moneda: cuando las joyas de Juana Carducha aparecen en las alforjas de su burro, uno de los soldados lo abofetea; y el noble, haciendo gala de su condición, lo

73 En la serie no hay la menor alusión a la polionomasia, tan característica de la poética cervantina. El paje siempre será Clemente y Juan tampoco trocará su nombre por el de Andrés al ingresar en el microcosmos gitano.

74 El Saffar, op. cit., p. 97.

75 Güntert, op. cit., p. 108. Lesley Lipson, "La palabra hecha nada": Mendacious Discourse in La Gitanilla", Cervantes: Bulletin of the Cervantes Society of America, Ix, 1 (1989), pp. 35-53, juzga a Clemente "doomed, not only by the essential requirements of the plot and the peace of mind of Andrés Caballero but by his poetic pursuit: outside the confines of the pure pastoral Cervantes's poets are frequently subject to criticism and ridicule" (p. 51). Sevilla Arroyo y Rey Hazas, $o p$. cit., p. XXXviII, opinan que su verdadera función se cifra en "corroborar que el increíble sacrificio [de Juan] [...] para merecer el amor de una gitana no es una locura ni un disparate, sino una prueba justificada por los méritos extraordinarios de la impar Preciosa”. Ver asimismo Casalduero, op. cit., p. 63. 
matará con su espada. Como gitano será preso y condenado a la horca de inmediato. Sin embargo, en cuanto se descubre su auténtico linaje, el corregidor no duda en liberarlo, por entender que con el crimen del militar reparó el oprobio sufrido. Entonces, Clemente será condenado, por más que actuara en defensa propia, mientras que a Juan se le exime de un delito cometido a sabiendas y por el cual, caso de conservar su disfraz, habría sido juzgado. En La gitanilla "in a way both integrated with and yet dissonantly distinct from the main plot, the author has taken us on a journey of subtle yet penetrating and disturbing glimpses into the often harsh inequalities and social tensions of the age"76.

Huelga abundar en que la crítica de Cervantes es un arma de doble filo: atenta contra las salvajes prácticas de los gitanos, pero también contra las paradojas del orden institucional, ya que "both court and country life in La gitanilla represent essentially problematical worlds where neither virtue, vice, nor truth are wholly absolute"77. De este modo habría que leer las pullas de Preciosa hacia el teniente y su mujer; y también el hecho de que, si la protagonista no va a la cárcel con el resto de gitanos, es porque su "hermosura en aquel día fue tanta que ninguno la miraba que no la bendecía"78.

Como cabía esperar, la adaptación de TVE no conservó ninguno de estos detalles; empezando por la historia de Clemente, que ahora no huye por un asesinato en defensa propia, sino hostigado por un noble que pretendía casarlo con su hija y que se sintió ofendido por su rechazo:

Yo, señor, estaba en casa de título a quien servía no como a señor, sino como a pariente. Este tenía una hija única, heredera suya. Queríame casar con ella, una doncella a quien yo no escogiera si no tuviera la voluntad sujeta a tan magno caballero. $Y$ tuve que decidir: ser rico y casado sin amor o poeta desposeído de toda fortuna. $\mathrm{Y}$ marché a Madrid y me puse al servicio del leal teniente, y allí estuve hasta que vos me conocisteis. Hasta el otro día, en que, para mi desgracia, un amigo de mi antiguo señor me reconoció (IV, 04:51).

76 Clamurro, "Enchantment and Irony", p. 82.

77 Gerli, op. cit., p. 37.

78 Cervantes, op. cit., p. 103. 
Mas la justicia no entra en juego en esta oportunidad. De igual forma, en la versión de TVE, la espada de Juan no acabará con ningún "bizarro soldado": la herida resulta aquí tan leve que no le impide capturar a su agresor. Tampoco Preciosa se librará de la celda gracias a su belleza. Los demás gitanos huyen y solo Andrés dará con sus huesos en el calabozo.

Sea como fuere, Clemente amenaza el amor de Preciosa y Juan, amén de servir como acicate para despertar los celos del protagonista. En el libreto de Rubio y Romá, este triángulo asume más peso que en la novela, ya desde la llegada del poeta al campamento. En el texto de Cervantes, Preciosa lo reconoce e informa a Andrés de su identidad, pero apenas habla con él durante todo el tiempo que los acompaña. De hecho, será la única que cuestione su permanencia: "todos fueron de parecer que se quedase en el aduar. Sólo Preciosa tuvo el contrario"79. En cambio, en la serie Preciosa no vacila en dialogar con Juan para calmar sus celos. Tras su reconciliación, Clemente sale malherido de la estancia en la que lo atendían. Juan lo nota y acaricia a Preciosa para marcar su territorio (Fig. 6). El poeta los ve y pierde el sentido. La abuela se acerca a la pareja y les advierte: "Mirad lo que hacéis y lo que vais a decir. ¿Quereisle ver, niña? Pues volved los ojos y vereisle desmayado" (III, 18:30).

Este consejo proviene de un lance anterior de la novela: la visita a la casa de Juan, en la que Preciosa baila para sus futuros suegros y celebra al poeta que le dedicó un soneto. En ese momento, Juan casi se desmaya y es el propio narrador el que previene a la gitanilla:

Mirad lo que habéis dicho, Preciosa, y lo que vais a decir; que esas no son alabanzas del paje, sino lanzas que traspasan el corazón de Andrés, que las escucha. ¿Quereislo ver, niña? Pues volved los ojos y vereisle desmayado encima de la silla, con un trasudor de muerte; no penséis, doncella, que os ama tan de burlas Andrés que no le hieran y sobresalten el menor de vuestros descuidos. Llegaos a él en hora buena, y decidle algunas palabras al oído, que vayan derechas al corazón y le vuelvan de su desmayo. ¡No, sino andaos a traer sonetos cada día en vuestra alabanza, y veréis cuál os le ponen ${ }^{80}$ !

79 Cervantes, op. cit., p. 92.

80 Cervantes, op. cit., p. 70. 
Se han invertido los roles: ahora es el paje el que sufre la celotipia; de ahí que los versos con los que Preciosa restaurase el ánimo de Juan se enderecen a Clemente:
Cabecita, cabecita, tente en ti, no te resbales, y apareja dos puntales de la paciencia bendita.
Solicita
la bonita confiancita; no te inclines a pensamientos rüines; verás cosas que toquen en milagrosas, Dios delante y san Cristóbal gigante ${ }^{81}$.

Podría aventurarse que en la adaptación de Aguado la gitana se apiada de Clemente y decide ayudarlo. Si no fuera por el siguiente diálogo:

Clemente. Preciosa.

Preciosa. Ya que me reconocéis, señor galán, ¿̇a qué venís aquí? (Clemente calla) De verdad que sois extraño; no sabéis responder sino con poemas y con silencios. Primero os vi como paje, luego como poeta, ahora no sabría decir de qué. ¿Quién sois en verdad?

Clemente. Ni yo mismo lo sé. Un hombre, un hombre solamente. Señor, paje o poeta. Qué más da.

Preciosa. ¿¿Un hombre decís? (Preciosa se acerca a Juan, que toma su mano y la rodea con sus brazos) ¿Y os desmayáis? (III, 20:00)

Ante tamaño desplante, el poeta queda devastado. Llama la atención la conducta de Preciosa en esta escena, pues se diría que quiere despertar los

81 Cervantes, op. cit., p. 71. Sobre este poema, ver Francisco Pérez Sánchez, "La doble transformación de un texto de Miguel de Cervantes en un poema alemán y en un Lied: el ensalmo de Preciosa 'Cabecita, cabecita' de la novela ejemplar La gitanilla", Cuadernos de Investigación Musical, III (2017), pp. 5-19. 
celos de ambos galanes, aunque a la postre se sitúa al lado de Juan (Fig. 7); no sin antes acusar al recién llegado de falta de hombría. Una actuación poco o nada ejemplar para un personaje que en el relato hizo bandera de su discreción.

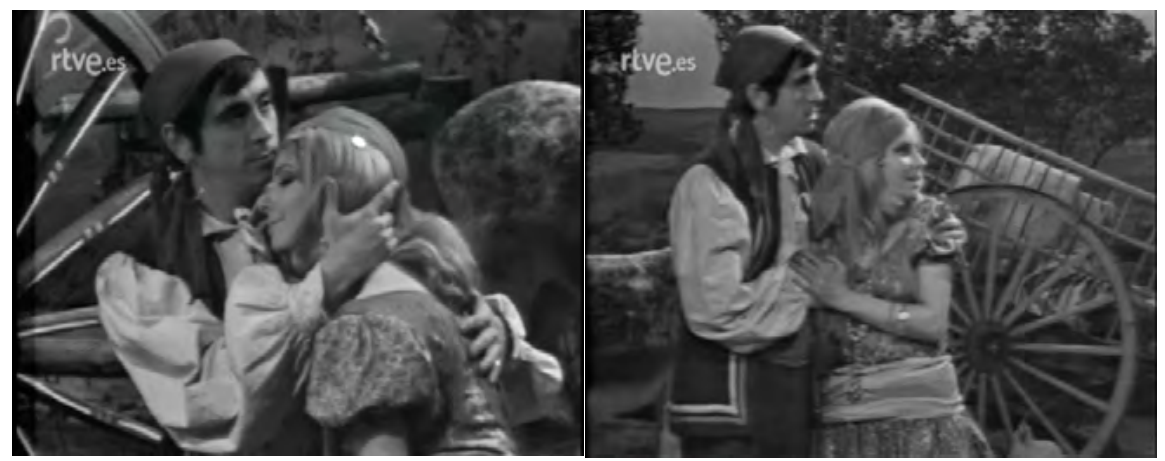

Fig. 6

Fig. 7

Sin embargo, Clemente habla enseguida con Juan y le cuenta que no tiene interés en Preciosa. Dicha confesión alivia al falso gitano, pero subraya la incoherencia de la escena previa. Y por desgracia también de la siguiente: Preciosa conversa con Clemente en una cantina y se disculpa por la actitud de Cárcamo, que los ve y sale del mesón, otra vez muerto de celos. Será entonces cuando lo aborde Juana Carducha (Ana en el trasvase de TVE), la cual pondrá a prueba su "noviciado". Juan la rehúye, pero se vuelve a tropezar con ella en la escalera que desemboca a los cuartos de la venta. La posadera se le insinúa delante de la protagonista, y él reitera su rechazo. A continuación, Ana mira resentida a la gitana mientras suena una música turbadora. Preciosa le paga con la misma moneda. Por fin, la ventera sube los peldaños en busca de las joyas que incriminarán a Juan.

Sin duda, esta secuencia se propuso aumentar la tensión, exacerbando así el poliedro amoroso, que en la novela queda en segundo plano. Lástima que los guionistas no se distanciaran del texto cervantino para incidir en esta vertiente: al insistir Clemente en su desinterés hacia la cíngara, los recursos de Rubio y Romá quedan al descubierto y su objetivo se evapora por completo. 


\subsection{El silencio de Preciosa}

Llama la atención que una muchacha tan aguda, vivaracha y tenaz como Preciosa se convierta en una dama muda y sumisa en cuanto se reconcilia con sus orígenes. Al decir de Rodríguez-Luis, "tan pronto como se descubre su identidad [...] deja casi por completo de hablar por sí misma, siendo el narrador quien nos informa de lo que responde" 82 . Como si una vez que se distancia del contexto gitano, se plegara al decoro institucional, deviniendo una joven ejemplar y perdiendo así su personalidad.

Este silencio ha sido interpretado de diversas maneras. En opinión de Clamurro, "Preciosa's docility is as marked a change as is the uncharacteristic immobility of the gypsies" y el final es "more darkly ironic and conservative than the initial gestures of female autonomy, dramatized in the opening scenes, would suggest" 83 . Johnson adelantó que "al ser restituida al lugar que de veras le corresponde en la sociedad, Preciosa cae bajo el control del padre y se incorpora al orden patricéntrico" ${ }^{84}$. Acerca de este particular, Pilar Alcalde no se muestra tan pesimista, pues Preciosa no habría dejado de hablar sólo por obediencia a sus progenitores, sino "para facilitarle a Constanza la incorporación a la nobleza. La única manera en que puede formar parte de la sociedad a la que quiere pertenecer es

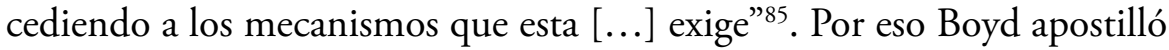
que "es precisamente la seguridad de su autoposesión lo que le permite hacer el papel de la hija sumisa ante sus padres"86. Y Díez fue un poco más allá: el silencio de Preciosa no es significativo, ya que "la poética de la novela exige un final emocionante y rápido y los personajes pierden la palabra, hombres y mujeres, en función de los objetivos globales de la narración en la que se insertan" ${ }^{87}$.

82 Rodríguez-Luis, op. cit., p. 137.

83 Clamurro, Beneath the Fiction, pp. 37 y 40.

84 Johnson, op. cit., p. 47.

85 Pilar Alcalde, "El poder de la palabra y el dinero en La gitanilla", Cervantes: Bulletin of the Cervantes Society of America, XVII, 2 (1997), pp. 122-132 (p. 129).

86 Boyd, op. cit., p. 14.

87 José Ignacio Díez Fernández, “The Rest is Silence: protagonista femenina y final de la novela en La gitanilla y La española inglesa”, Cálamo FASPE, LXII (2013), pp. 69-76 (p. 76). 
Bajo la mudez de la joven gitana se intuye, en suma, un signo de conservadurismo, una pulla de Cervantes contra la sociedad a la que su protagonista acaba regresando, como una estrategia de adaptación, o como mera contingencia.

De ahí que, al igual que en la novela, la gitanilla de la serie de TVE calle desde que conoce su alcurnia ${ }^{88}$. Con excepción, en primer lugar, del ruego que hace a su padre para que saque a Juan de la cárcel. Cuando su caballero regresa, solo dirá una palabra más: “AAbuela!” (v, 23: 29); lo que da pie a que la vieja ultime: "Dices bien, que ellos son tus padres, pero yo abuela tuya soy y seré”, reivindicando así la idiosincrasia de la que nunca renegará la protagonista. En ese momento se escucha una música subjetiva de raíz flamenca que remite al aduar. Y Preciosa pasa de los brazos de su abuela a los de Juan. Mientras se hunde en su pecho, la cámara se aproxima a su rostro hasta encuadrarlo en un primerísimo plano que se funde con otro de sus antiguos congéneres (Fig. 8). Las palmas ensordecen la banda sonora de Rafael Beltrán. Preciosa mira al infinito. Los gitanos bailan y el foco se desplaza hacia una carreta que el realizador recorre con planos cortos, deteniéndose sobre el extremo de una de sus vigas. Justo donde se colocaría el yugo, se posa un cartel con la palabra "fin".

La triada Rubio-Romá-Aguado nos brinda así un desenlace agridulce: Preciosa acaba casándose con el hombre al que ama y se reencuentra con sus padres biológicos, a costa de renunciar a su vida como gitana. El yugo del matrimonio despide y unce sus días de libertad; de ahí el último plano (Fig. 9). No obstante, si Preciosa, como cíngara, sentía dentro de sí "cierto espiritillo fantástico que a grandes cosas le llevaba" ${ }^{89}$, al abrazar la nobleza, se agitarán en su interior los ecos y el compás de su flamenca crianza.

88 En la novela, Preciosa no presenciaba la confesión de su abuela, y la corregidora ratificaba su maternidad más tarde, a través de una marca de nacimiento que su hija tenía bajo la teta izquierda y por los dos últimos dedos del pie derecho, que se hallaban trabados. En cambio, en la versión de Aguado, Preciosa escucha el relato de primera mano y la madre comprueba las palabras de la vieja tras haber advertido en el brazo de la gitanilla un lunar idéntico al que tenía su pequeña.

89 Cervantes, op. cit., p. 57. 


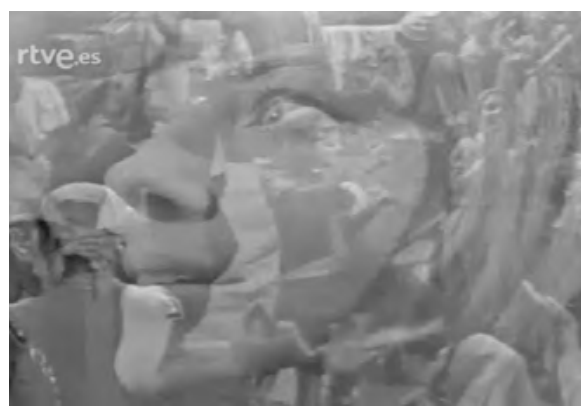

Fig. 8

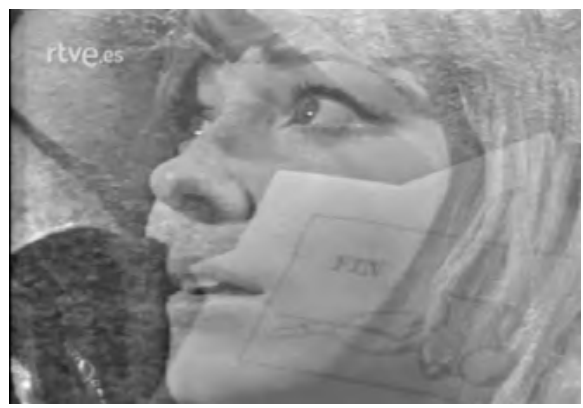

Fig. 9 